Supporting information

\title{
Design of a tris-heteroleptic Ru(II) complex with red-light excitation and remarkably improved photobiological activity
}

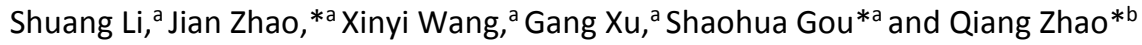 \\ a Jiangsu Province Hi-Tech Key Laboratory for Biomedical Research and Pharmaceutical Research Center, School \\ of Chemistry and Chemical Engineering, Southeast University, Nanjing 211189, China. E-mail: \\ zhaojianzhaokuan@163.com; 2219265800@qq.com
}

${ }^{\mathrm{b}}$ Key Laboratory for Organic Electronics and Information Displays, Institute of Advanced Materials (IAM), Jiangsu National Synergetic Innovation Center for Advanced Materials (SICAM), Nanjing University of Posts and

Telecommunications(NUPT), Nanjing 210023, P. R. China. E-mail: iamqzhao@njupt.edu.cn

\footnotetext{
Table of Contents:

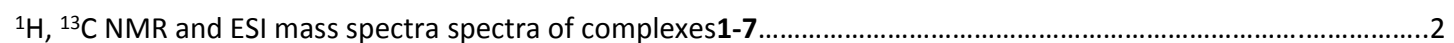

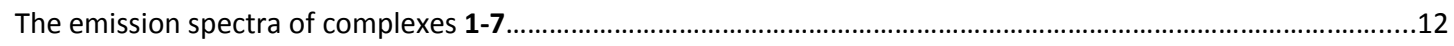

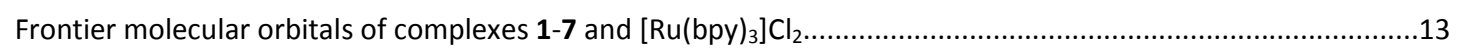

${ }^{1} \mathrm{O}_{2}$ generation of complexes 1-7 and $\left[\mathrm{Ru}(\mathrm{bpy})_{3}\right] \mathrm{Cl}_{2}$ under $650 \mathrm{~nm}$ irradiation...................................................16

Dose-dependent drug efficacy for complexes 1-7 and $\left[\mathrm{Ru}(\mathrm{bpy})_{3}\right] \mathrm{Cl}_{2}$ on $\mathrm{A} 549$ and $\mathrm{HepG2}$ cells............................17

Confocal fluorescence images of calcein AM / propidium iodide co-stained A549 cells...........................................18

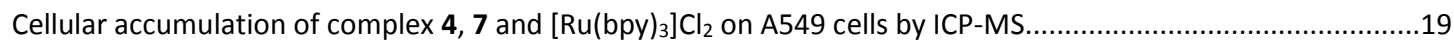

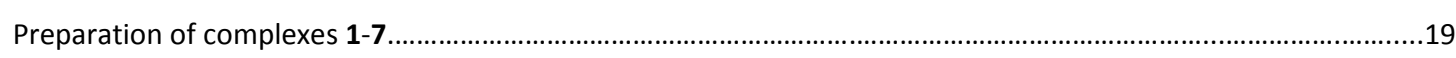

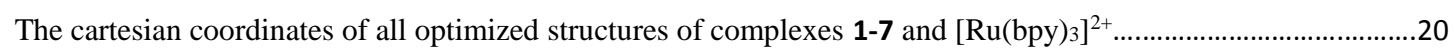




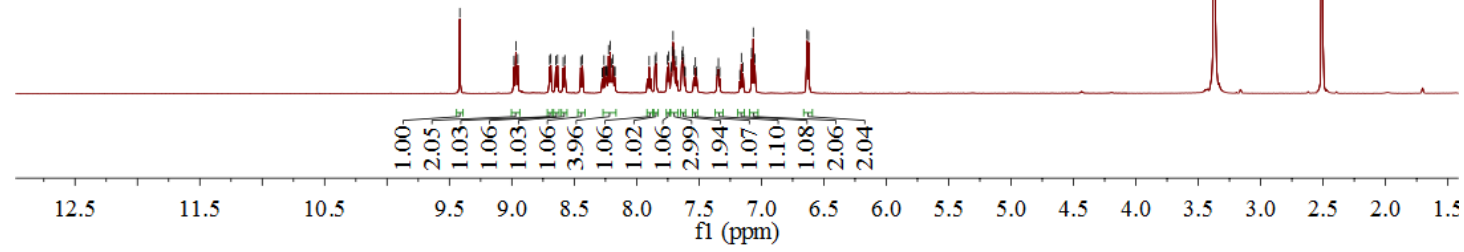

Fig. $\mathbf{S 1}{ }^{1} \mathrm{H}$ NMR spectrum of complex 1 .

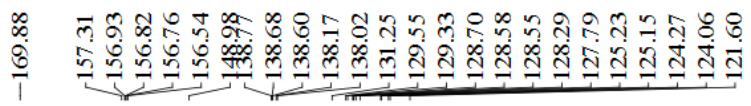

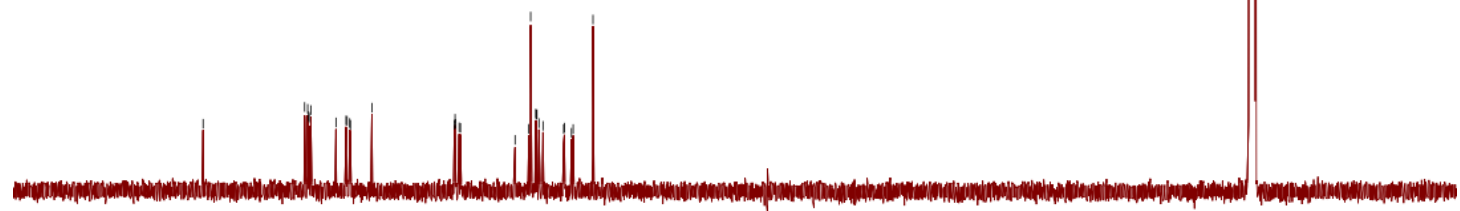

190

180

$150 \quad 140$

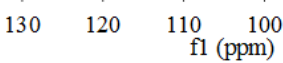

90

70

$\begin{array}{lllll}60 & 50 & 40 & 30 & 20\end{array}$

Fig. S2 ${ }^{13} \mathrm{C}$ NMR spectrum of complex 1. 


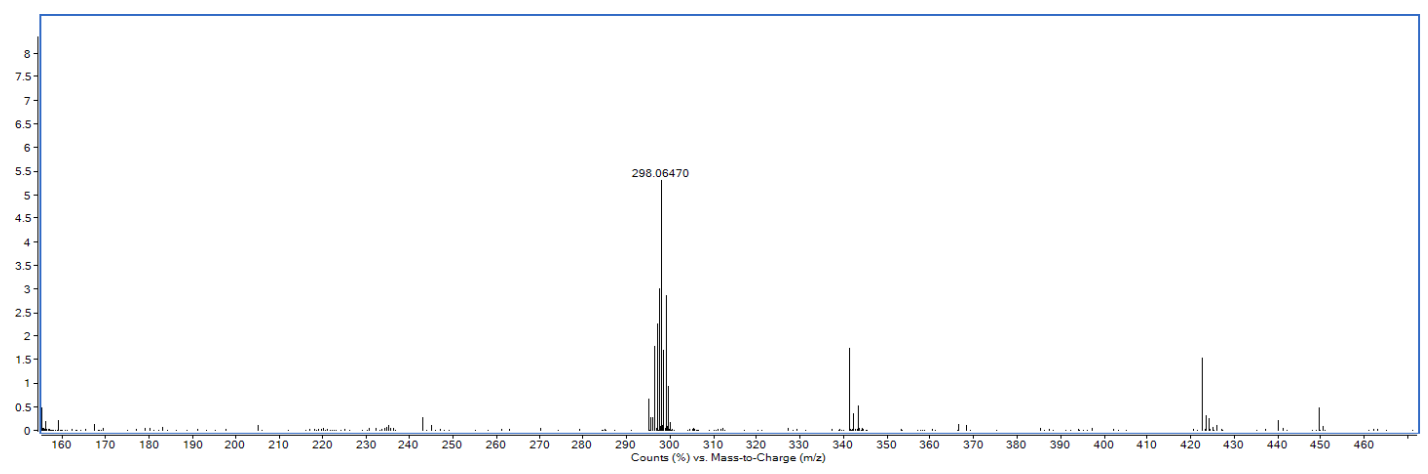

Fig. S3 ESI mass spectrum of complex 1.

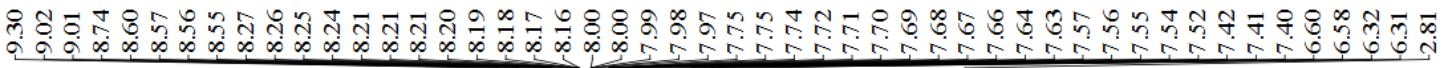

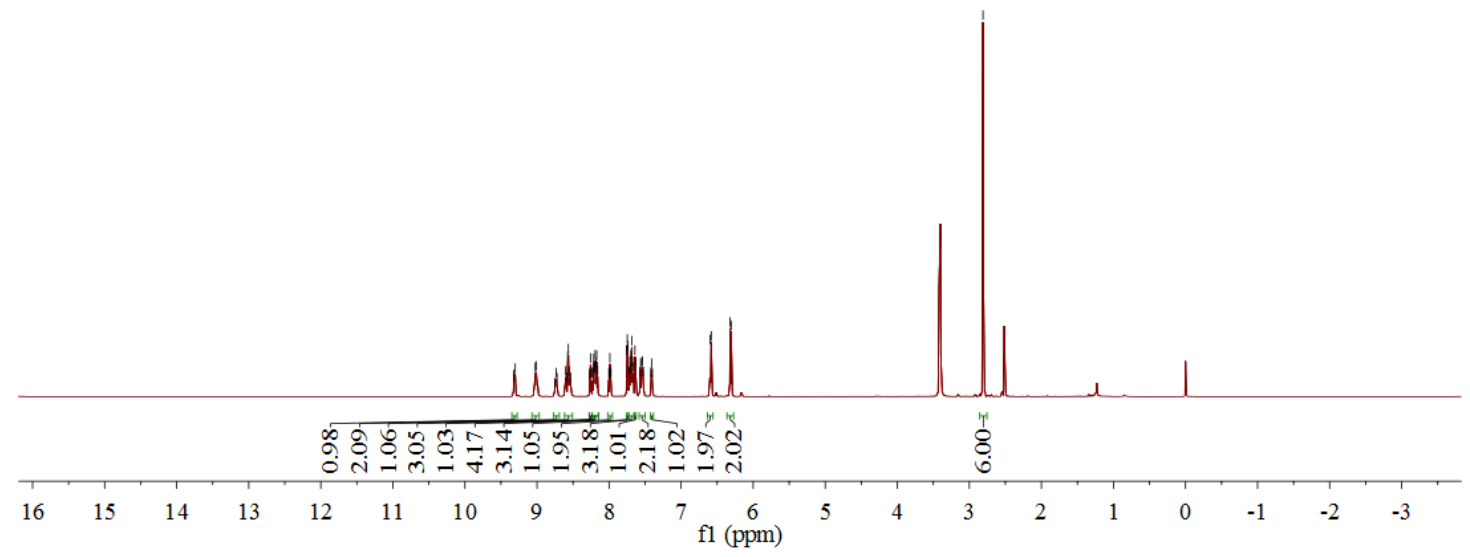

Fig. S4 ${ }^{1} \mathrm{H}$ NMR spectrum of complex 2 . 


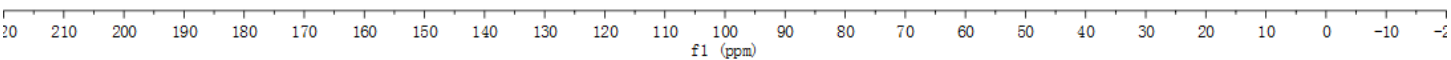

Fig. S5 ${ }^{13} \mathrm{C}$ NMR spectrum of complex 2 .

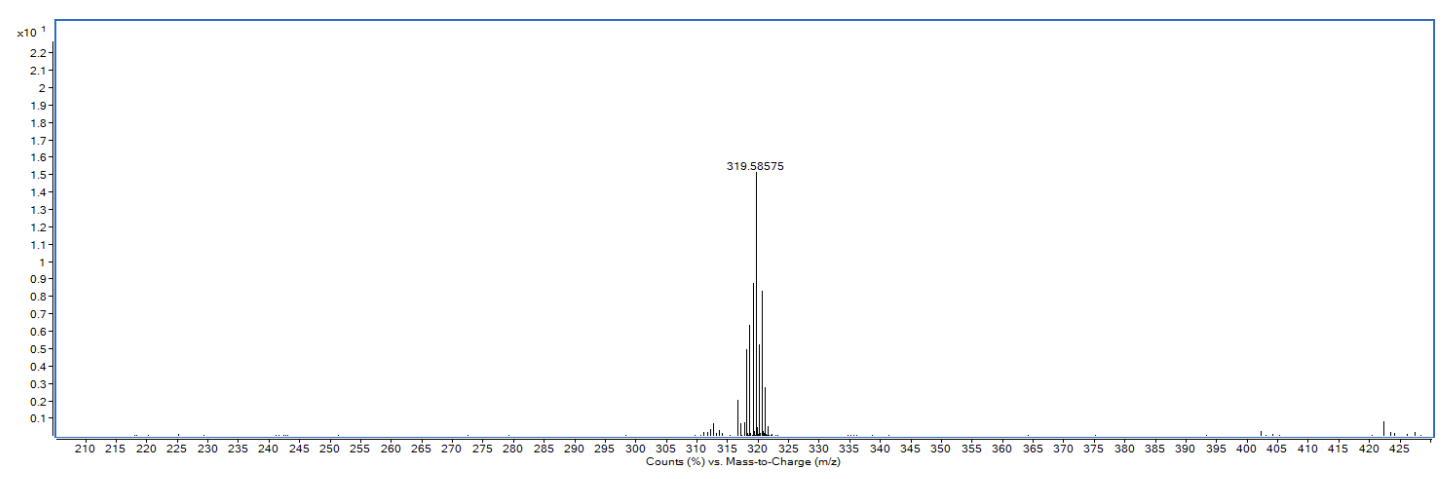

Fig. S6 ESI mass spectrum of complex 2. 


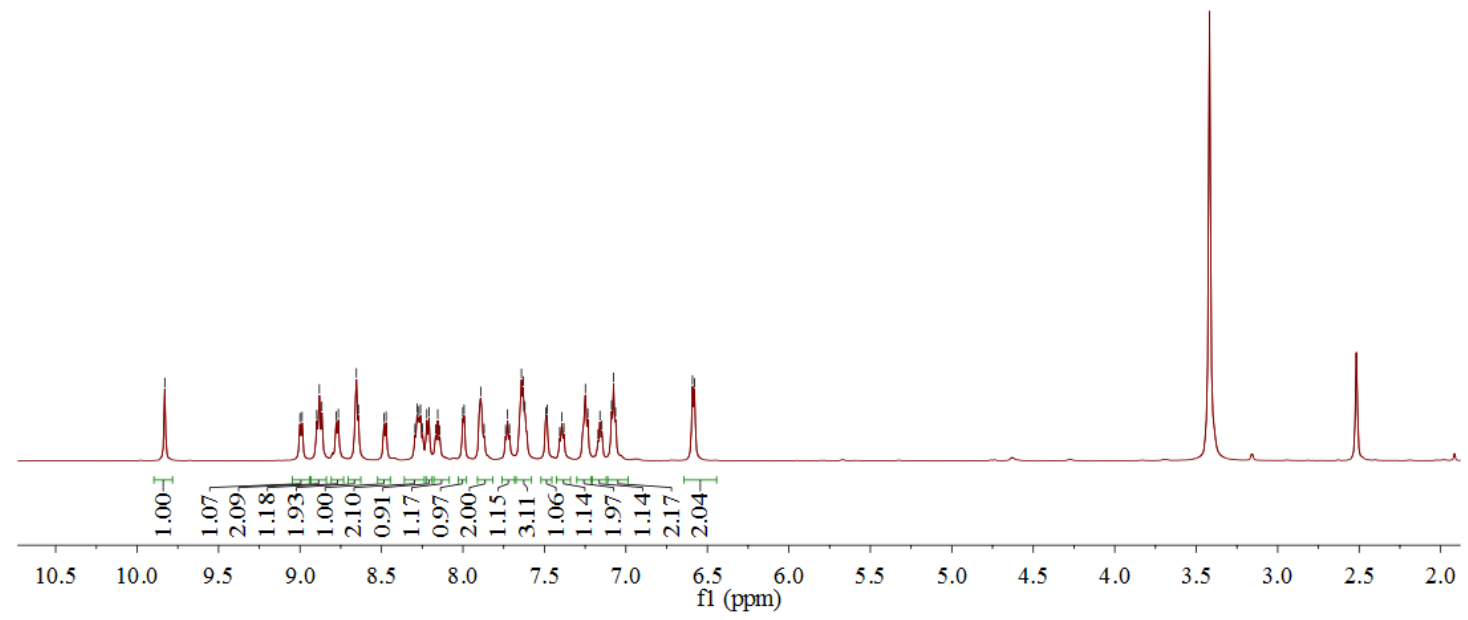

Fig. $\mathbf{S 7}{ }^{1} \mathrm{H}$ NMR spectrum of complex 3 .
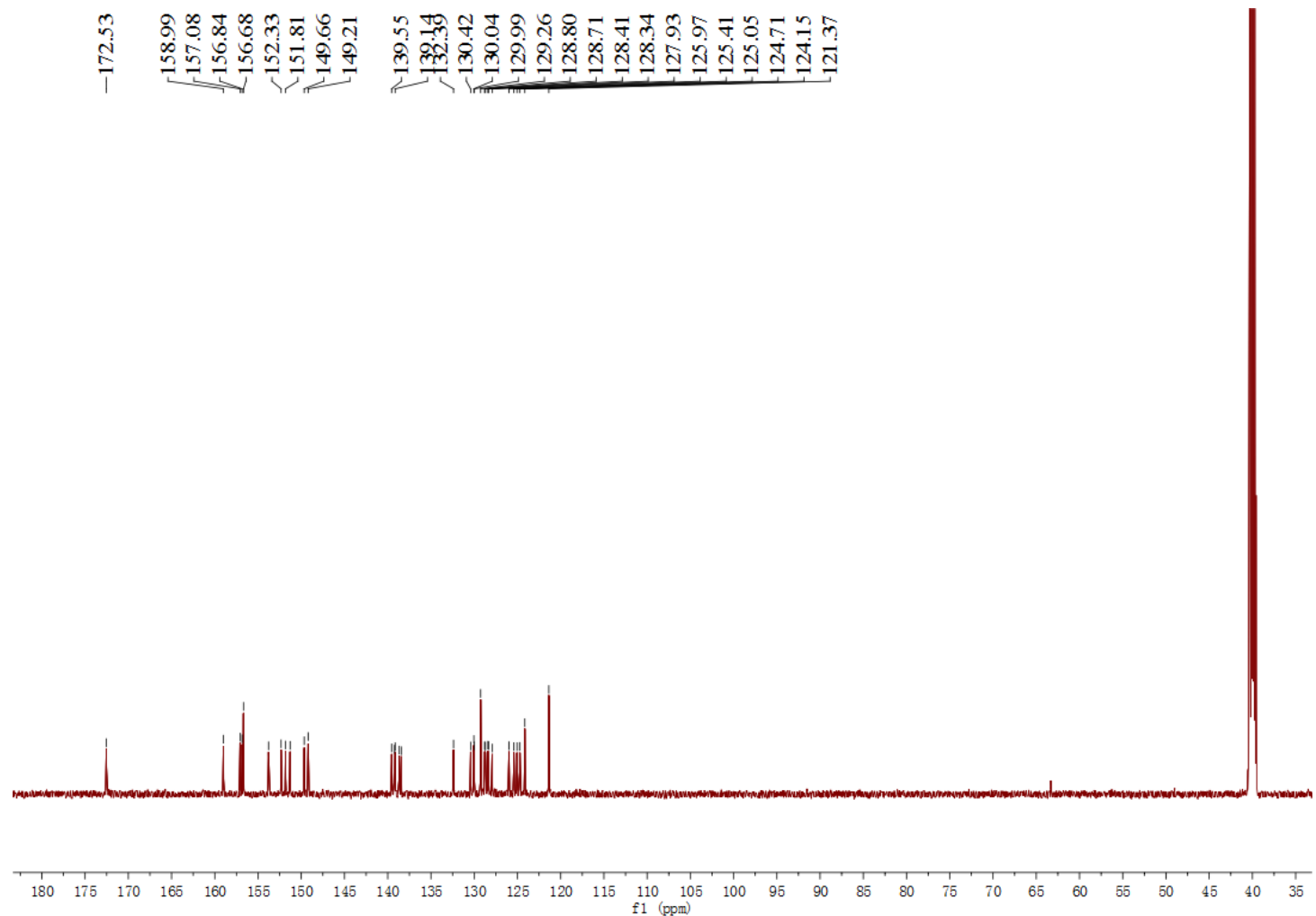

Fig. $\mathbf{S 8}{ }^{13} \mathrm{C}$ NMR spectrum of complex 3. 


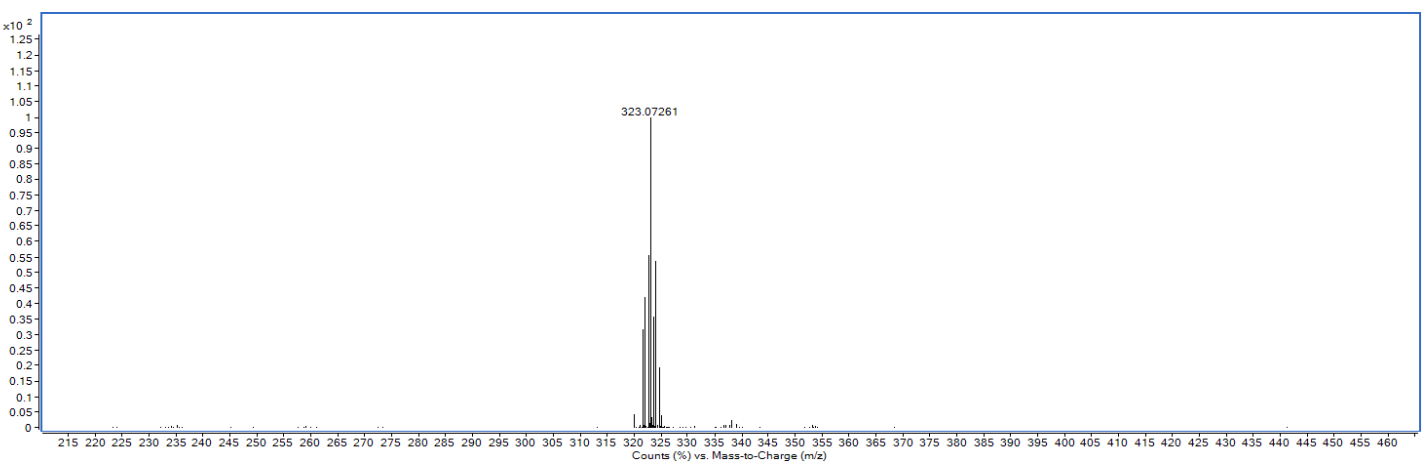

Fig. S9 ESI mass spectrum of complex 3.

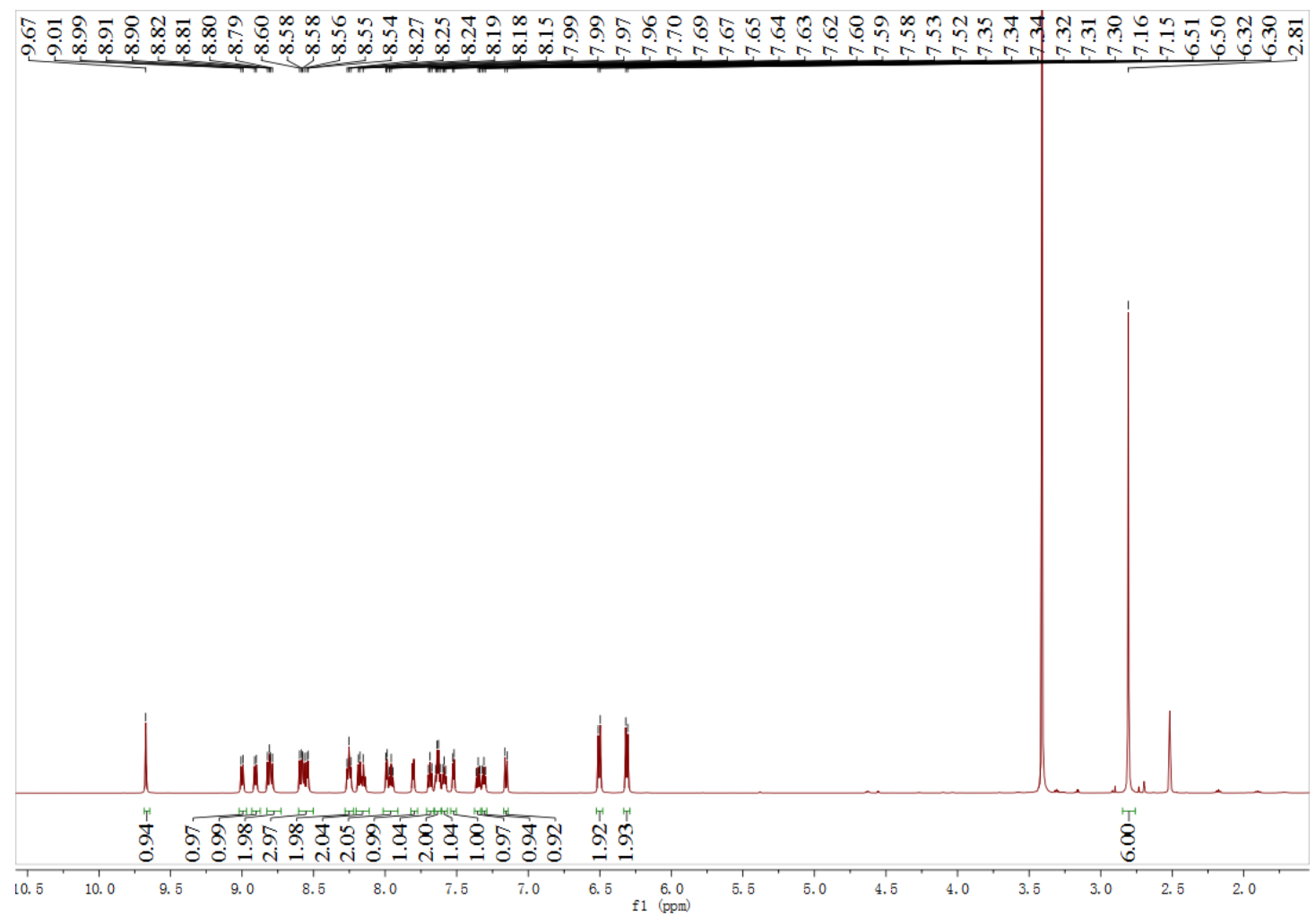

Fig. $S 10^{1} \mathrm{H}$ NMR spectrum of complex 4 . 


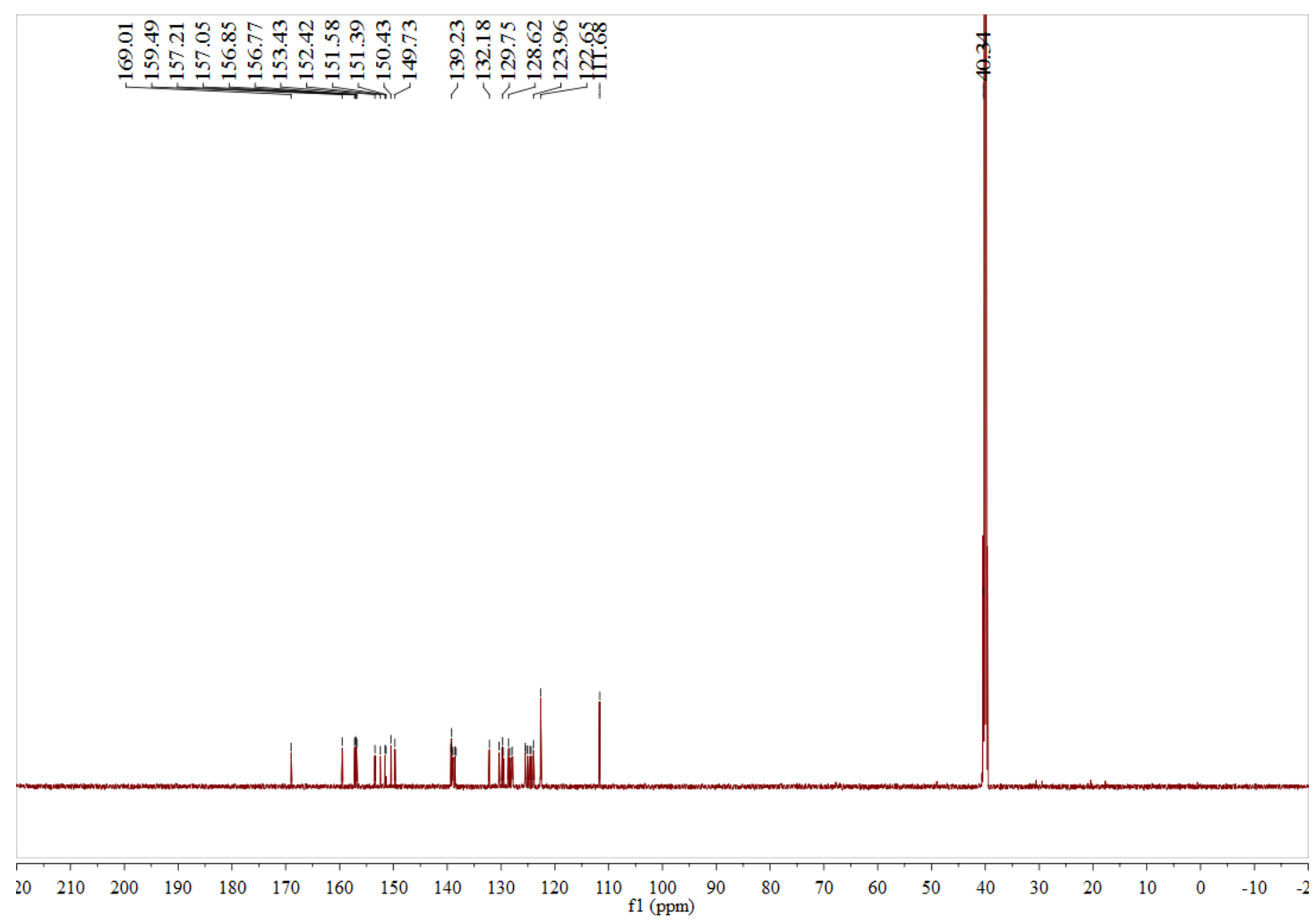

Fig. S11 ${ }^{13} \mathrm{C}$ NMR spectrum of complex 4.

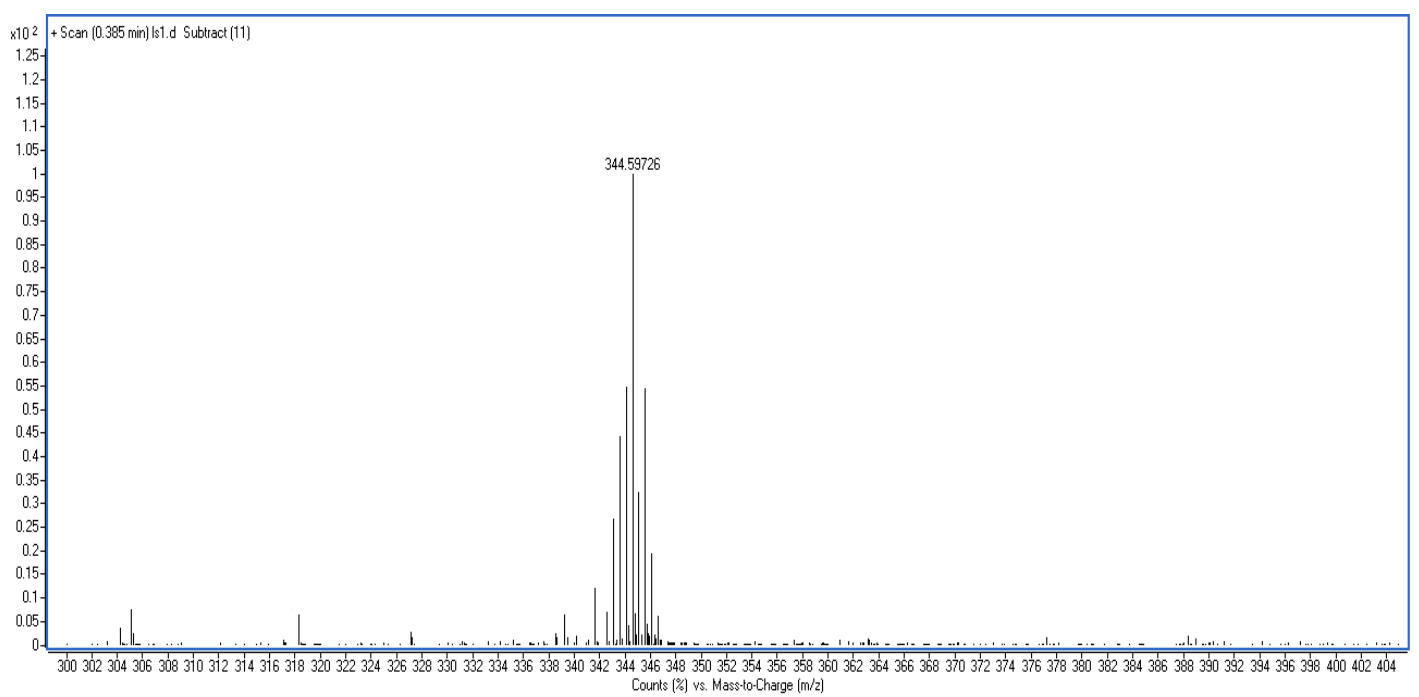

Fig. S12 ESI mass spectrum of complex 4. 


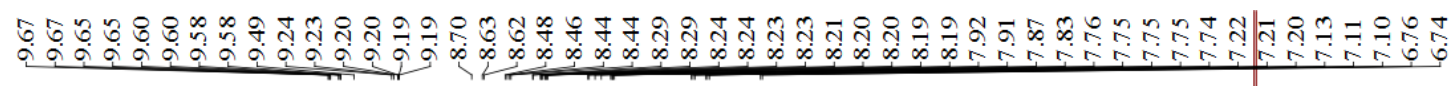

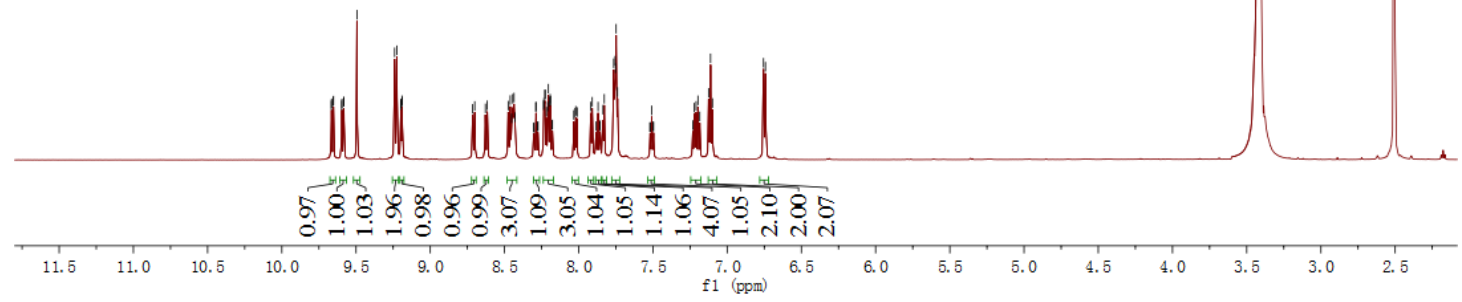

Fig. $\mathbf{S 1 3}{ }^{1} \mathrm{H}$ NMR spectrum of complex 5 .

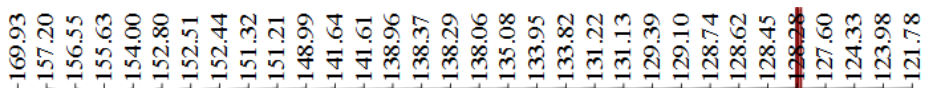

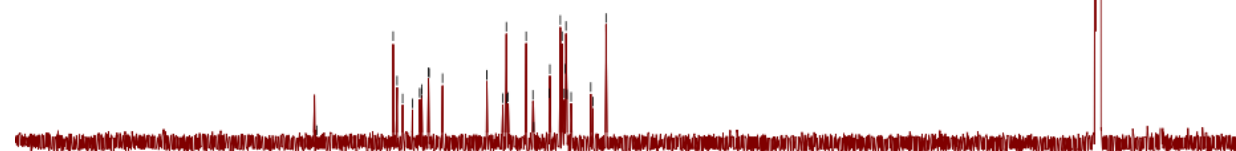

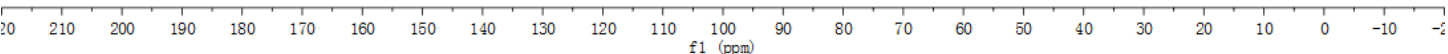

Fig. S14 ${ }^{13} \mathrm{C}$ NMR spectrum of complex 5 . 


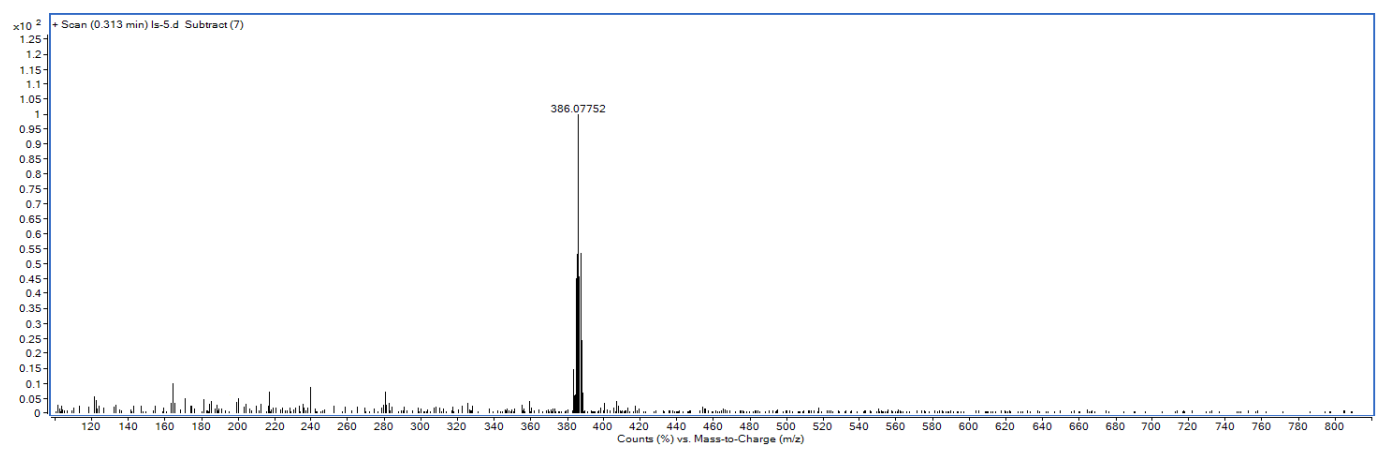

Fig. S15 ESI mass spectrum of complex 5.

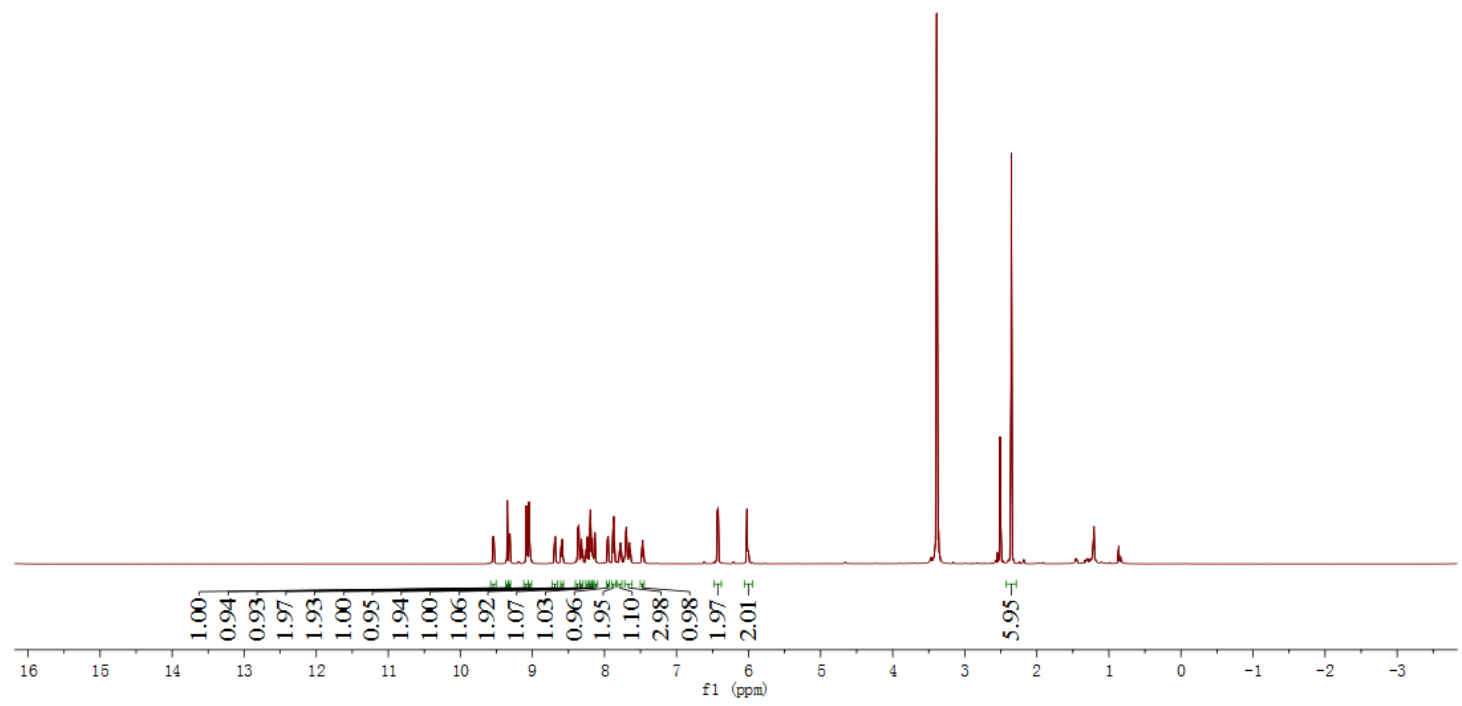

Fig. $\mathbf{S 1 6}{ }^{1} \mathrm{H}$ NMR spectrum of complex 6 . 

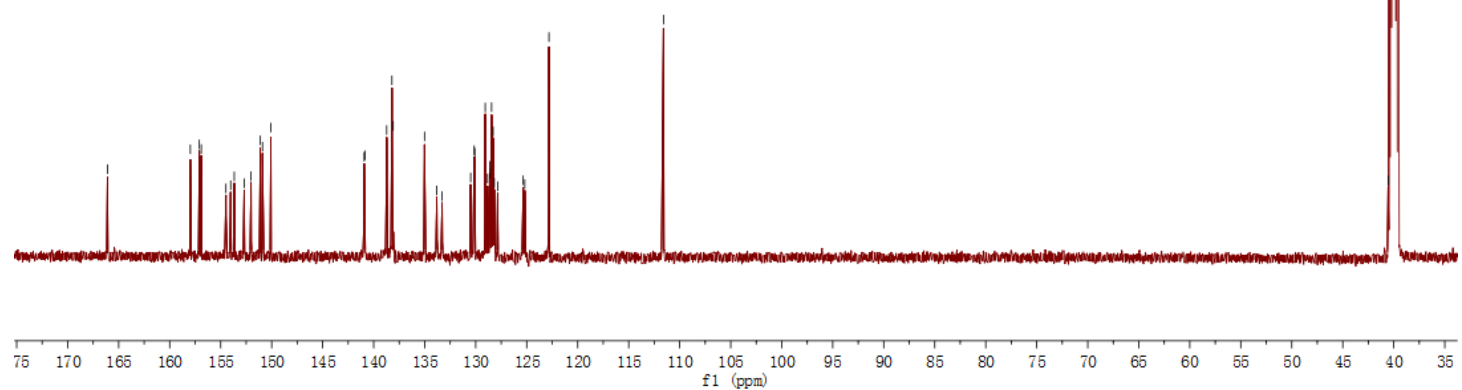

Fig. S17 ${ }^{13} \mathrm{C}$ NMR spectrum of complex 6.

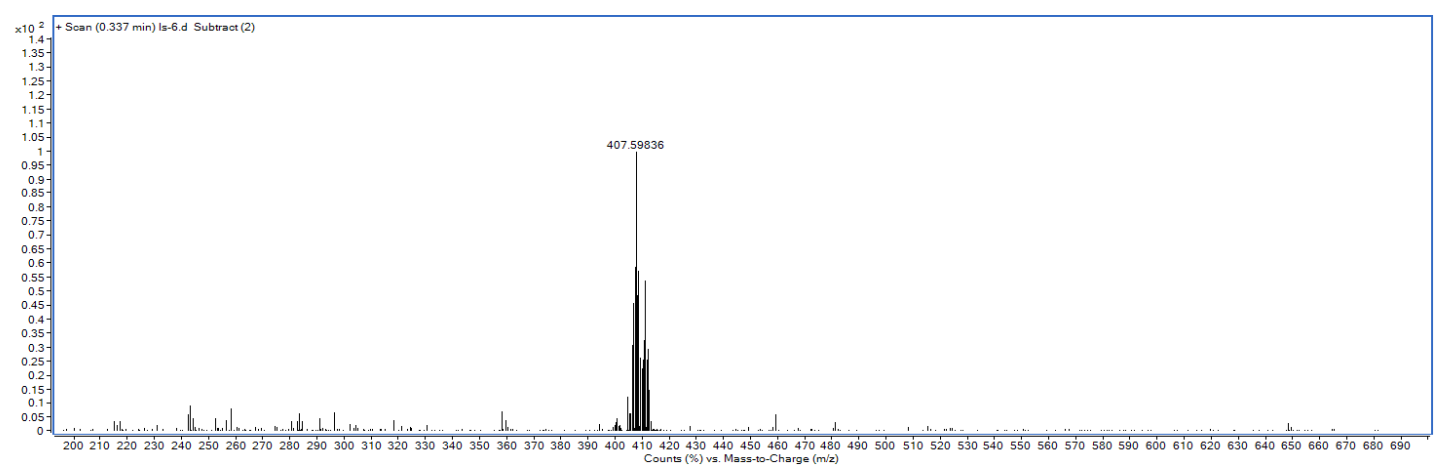

Fig. S18 ESI mass spectrum of complex 6 . 


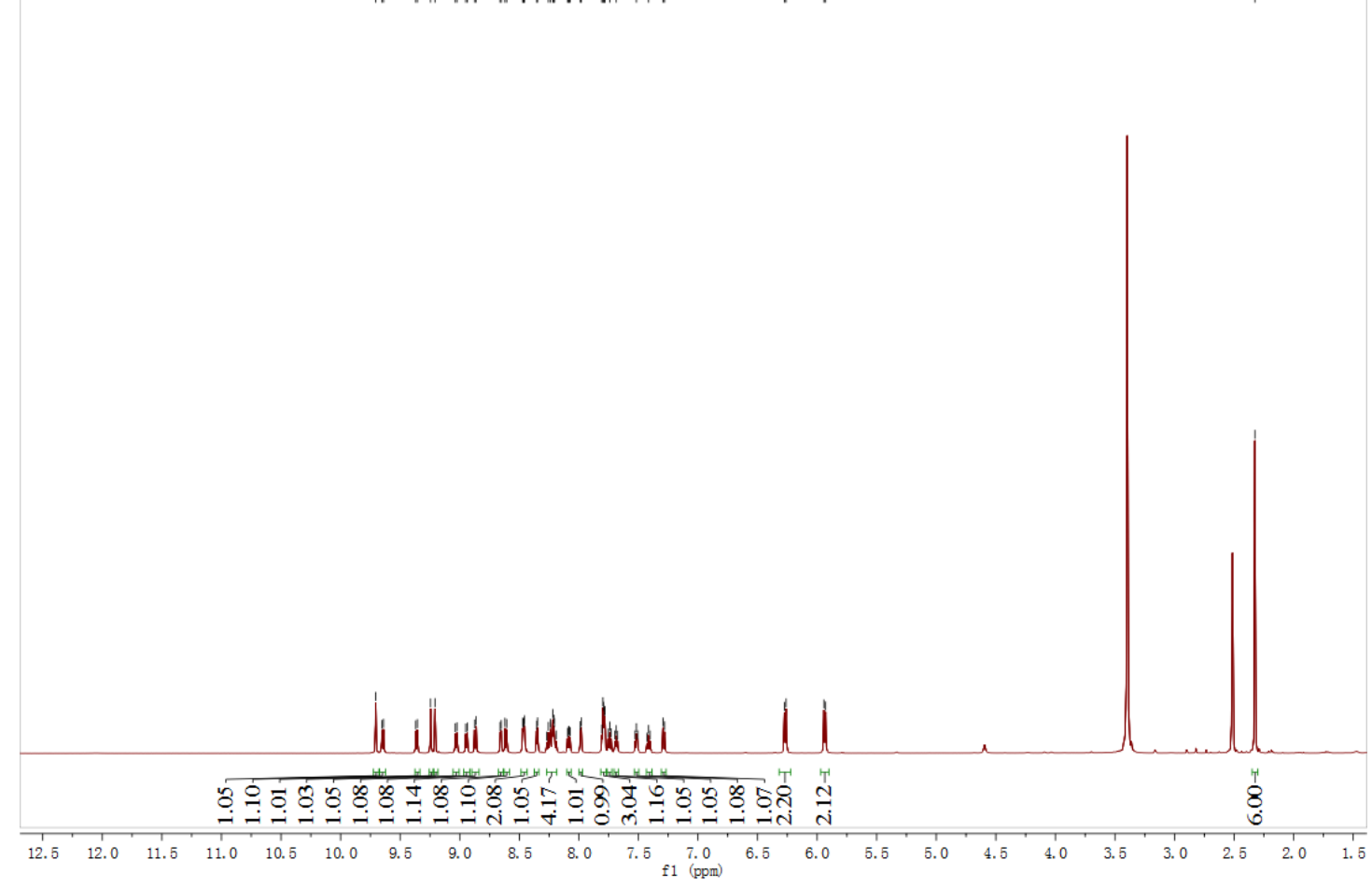

Fig. S19 ${ }^{1} \mathrm{H}$ NMR spectrum of complex 7.

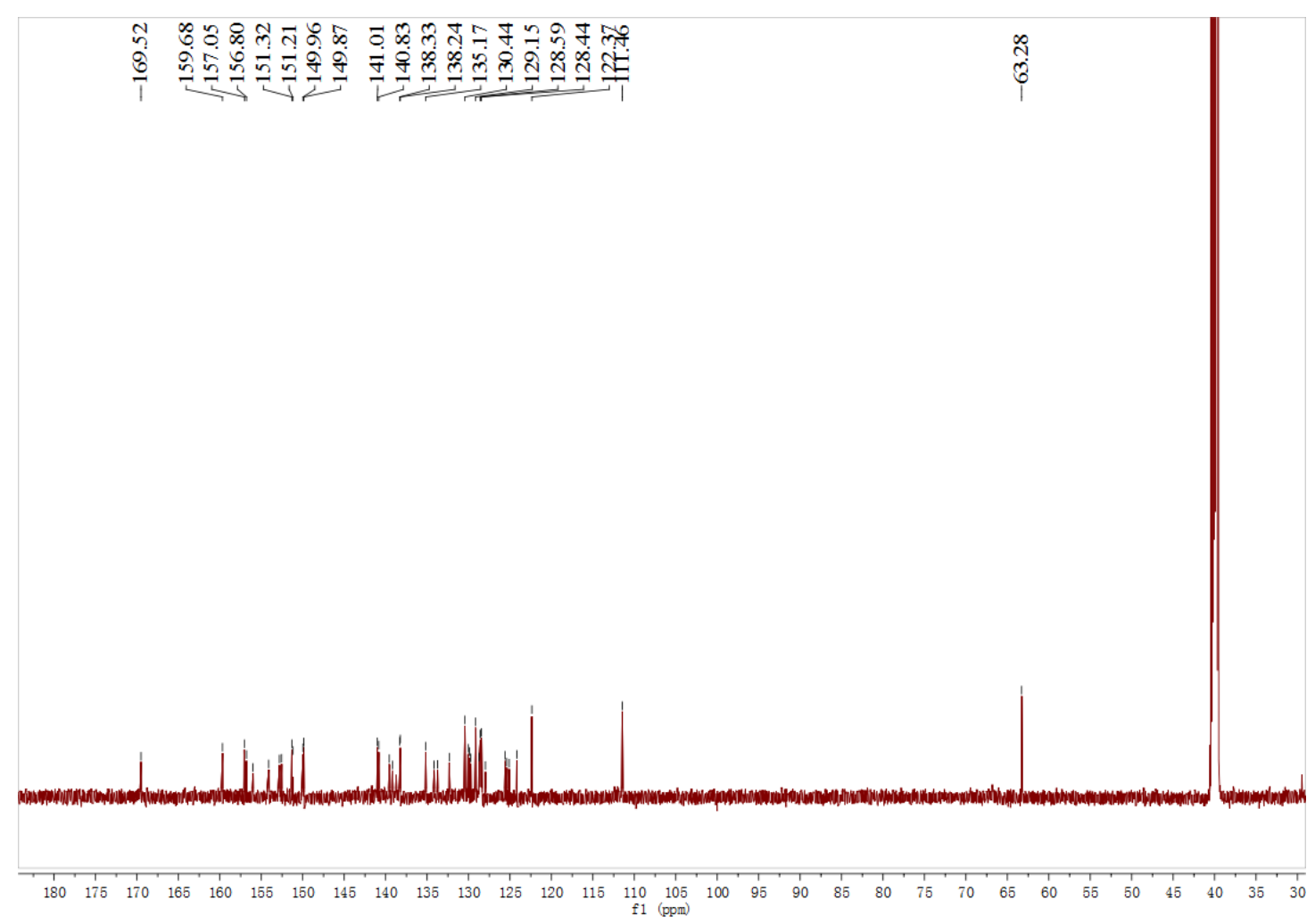

Fig. $\mathbf{S 2 0}{ }^{13} \mathrm{C}$ NMR spectrum of complex 7 . 


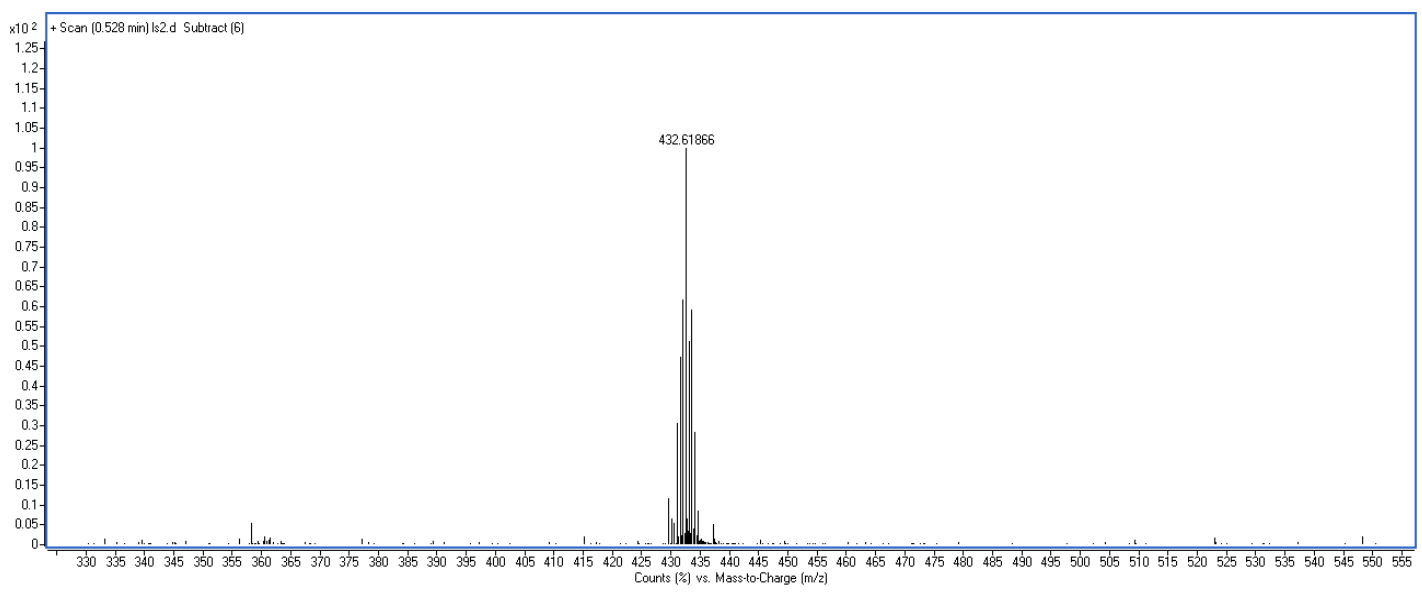

Fig. S21 ESI mass spectrum of complex 7.

(a)

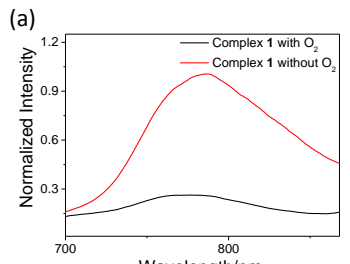

(e)

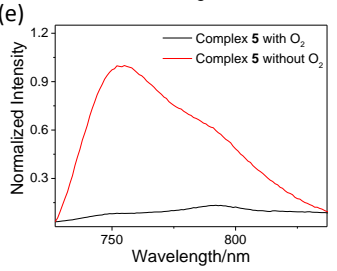

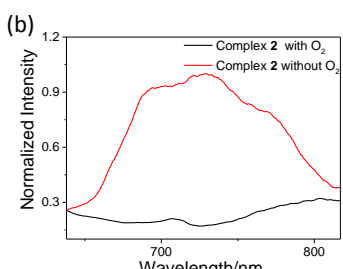

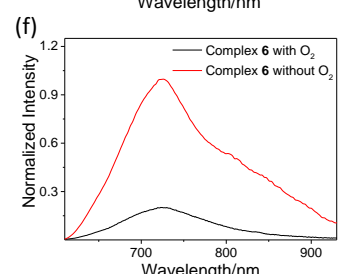

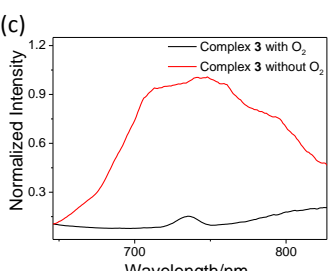
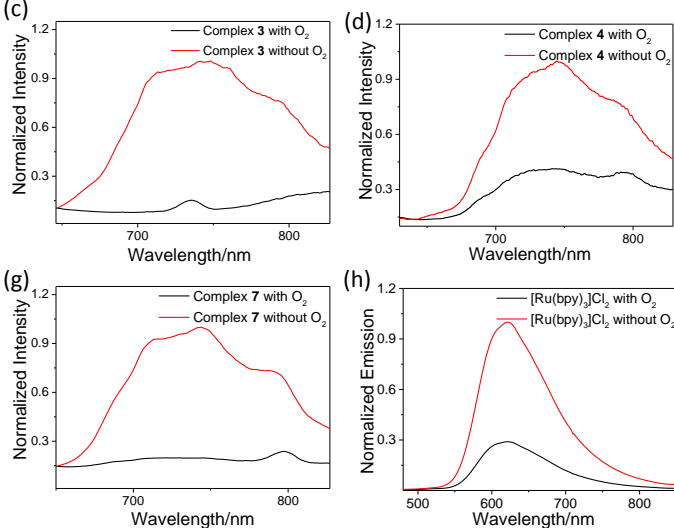

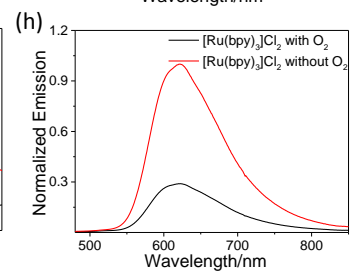

Fig. S22 The emission spectra of (a) complex $1\left(\lambda_{\mathrm{ex}}=490 \mathrm{~nm}\right)$, (b) complex $2\left(\lambda_{\mathrm{ex}}=488 \mathrm{~nm}\right)$, (c) complex $3\left(\lambda_{\mathrm{ex}}=\right.$ $490 \mathrm{~nm}),(\mathrm{d})$ complex $4\left(\lambda_{\mathrm{ex}}=510 \mathrm{~nm}\right)$, (e) complex $5\left(\lambda_{\mathrm{ex}}=490 \mathrm{~nm}\right)$, (f) complex $6\left(\lambda_{\mathrm{ex}}=490 \mathrm{~nm}\right)$, (g) complex 7 $\left(\lambda_{\mathrm{ex}}=510 \mathrm{~nm}\right),(\mathrm{h})\left[\mathrm{Ru}(\mathrm{bpy})_{3}\right] \mathrm{Cl}_{2}\left(\lambda_{\mathrm{ex}}=449 \mathrm{~nm}\right)$ in aerated and deaerated methanol at room temperature. 

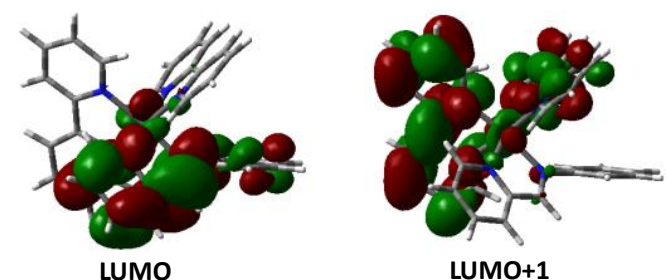

LUMO+1
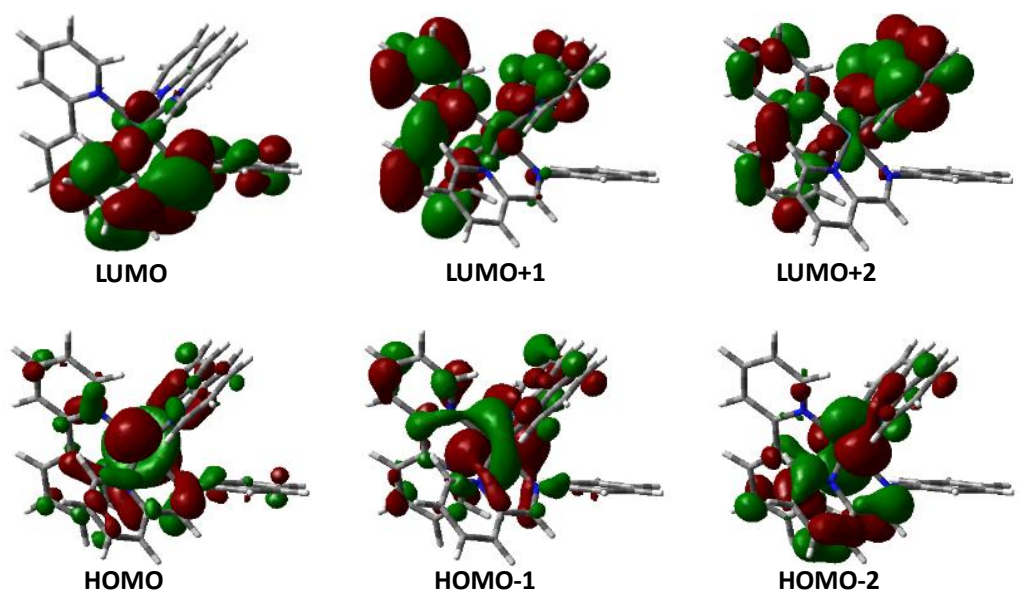

Fig. S23 Frontier molecular orbitals of complex 1.
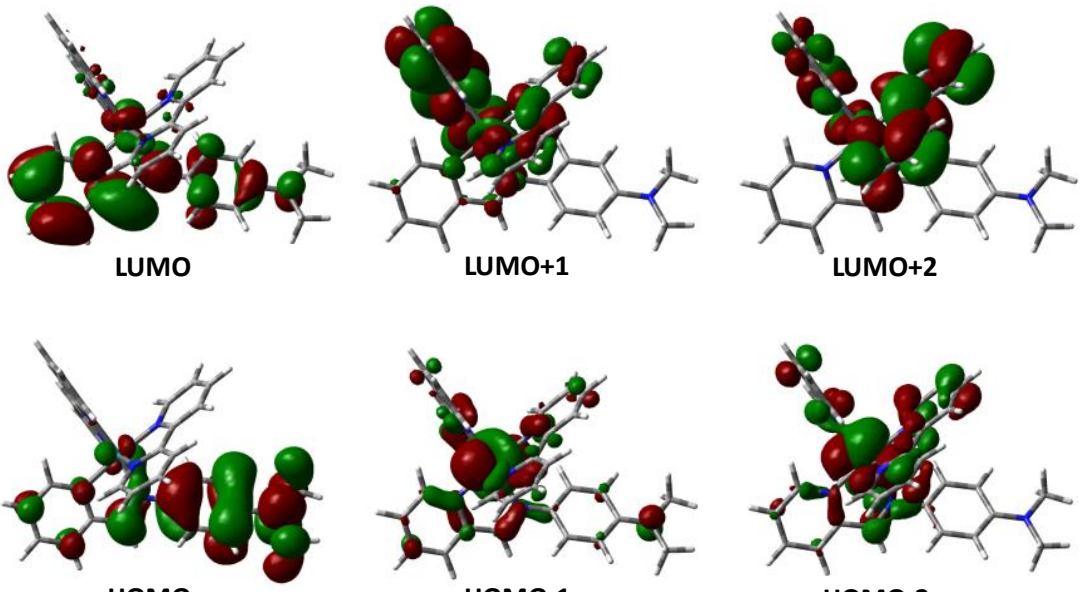

HOMO
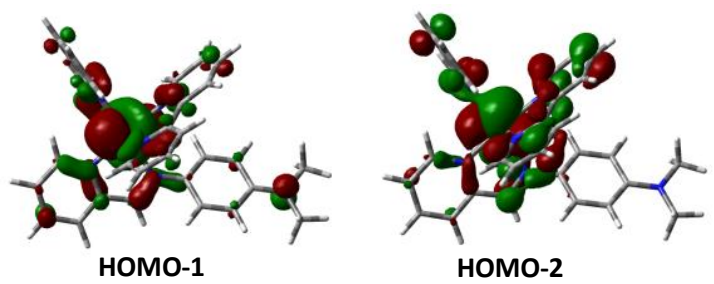

Fig. S24 Frontier molecular orbitals of complex 2. 


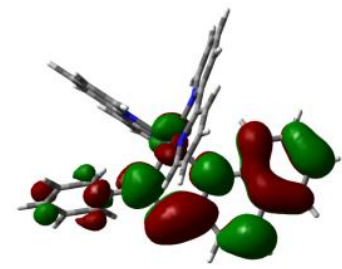

LUMO

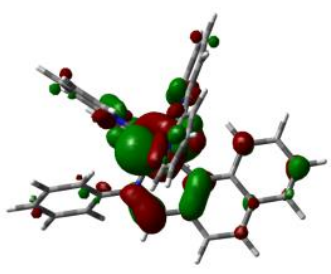

HOMO

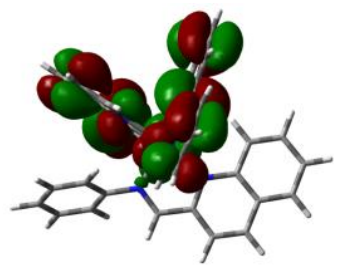

LUMO+1

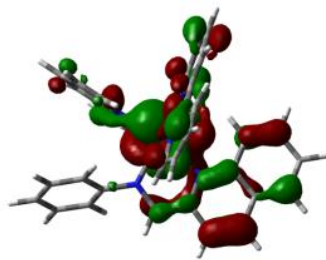

HOMO-1

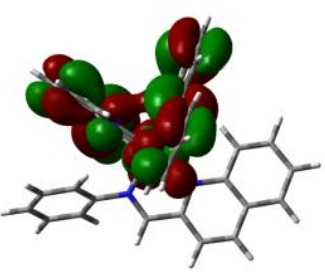

LUMO+2

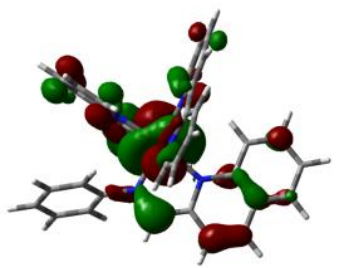

HOMO-2

Fig. S25 Frontier molecular orbitals of complex 3

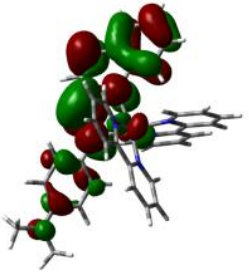

LUMO

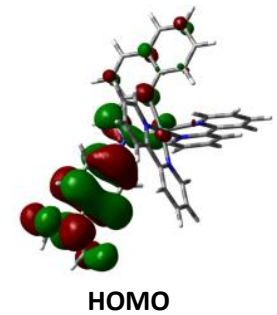

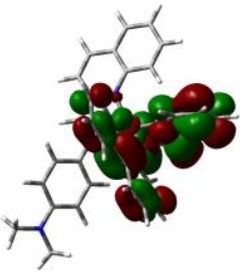

LUMO+1

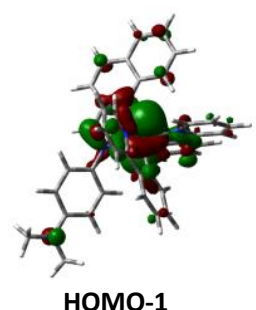

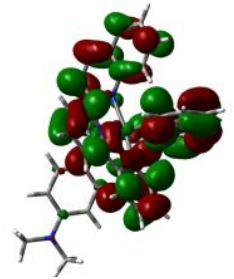

LUMO+3

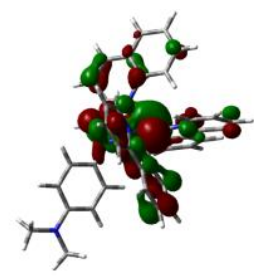

HOMO-3

Fig. S26 Frontier molecular orbitals of complex 4. 


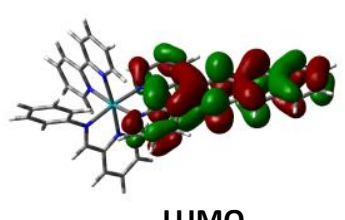

LUMO

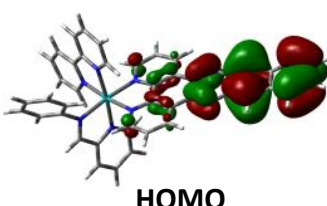

HOMO
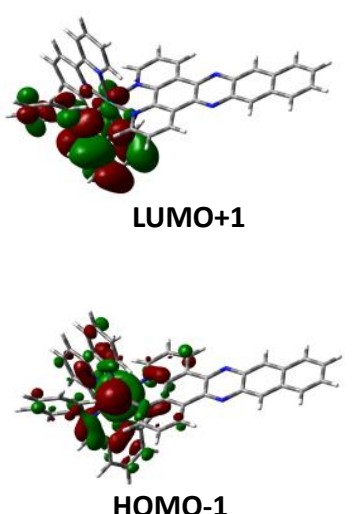

HOMO-1

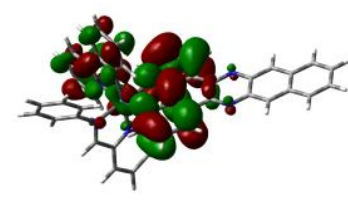

LUMO+2

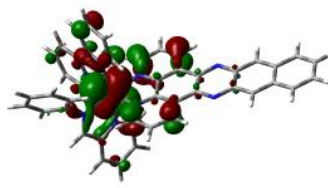

HOMO-2

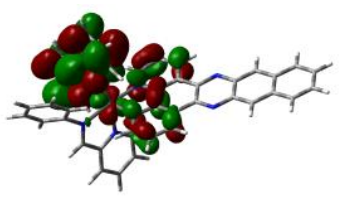

LUMO+3

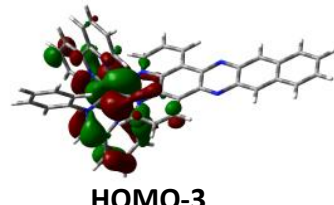

HOMO-3

Fig. S27 Frontier molecular orbitals of complex 5.

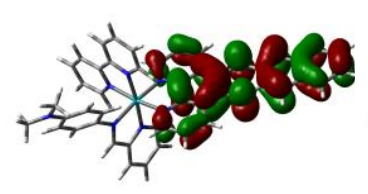

LUMO

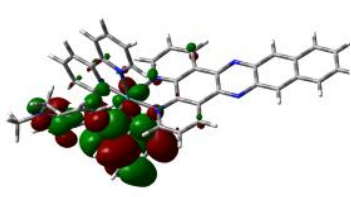

LUMO+1

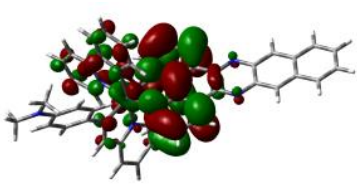

LUMO+2

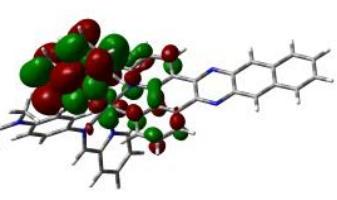

LUMO+3

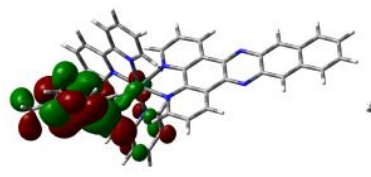

HOMO

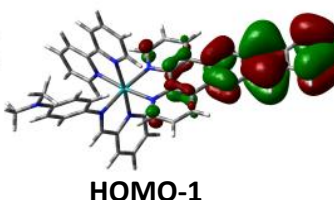

HOMO-1

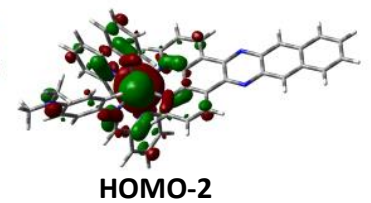

HOMO-2

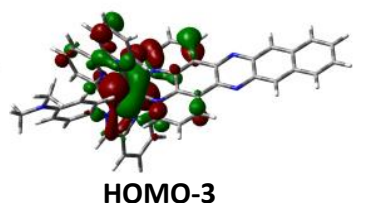

HOMO-3

Fig. S28 Frontier molecular orbitals of complex 6.

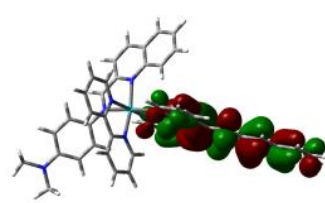

LUMO

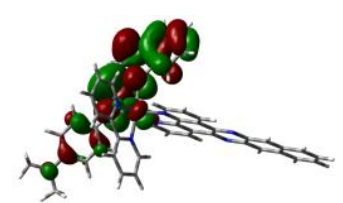

LUMO+1

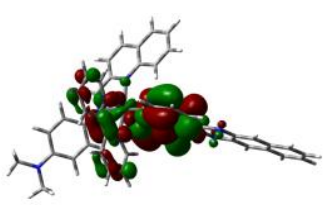

LUMO+2

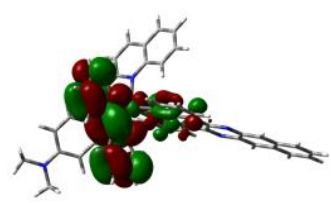

LUMO+3

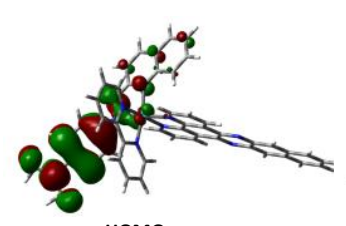

номо

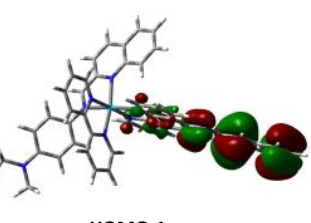

HOMO-1

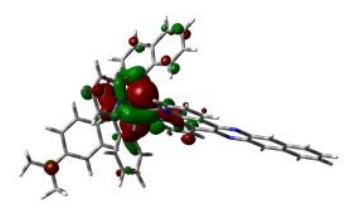

HOMO-2

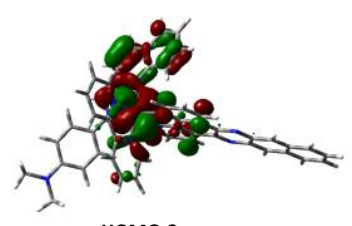

номо-3

Fig. S29 Frontier molecular orbitals of complex 7. 


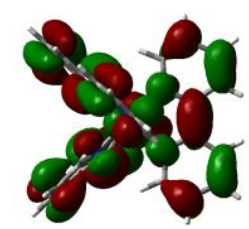

LUMO

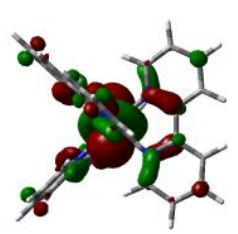

номо

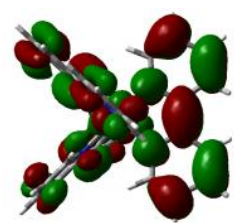

LUMO+1

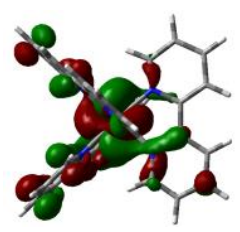

HOMO-1

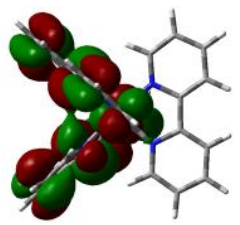

LUMO+2

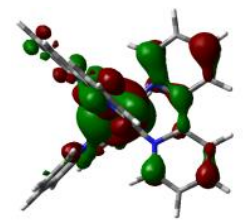

HOMO-2

Fig. S30 Frontier molecular orbitals of $\left[\mathrm{Ru}(\mathrm{bpy})_{3}\right] \mathrm{Cl}_{2}$.
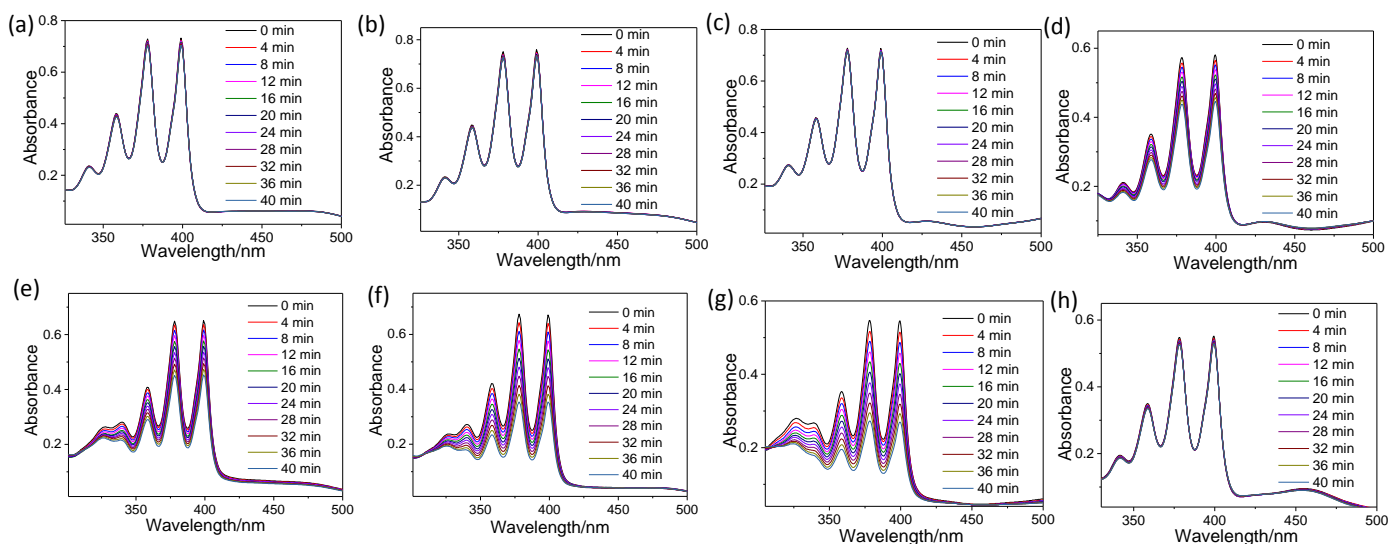

Fig. S31 The absorption spectra of ABDA $(50 \mu \mathrm{M})$ in the presence of $\mathbf{1}$ (a), $\mathbf{2}$ (b), $\mathbf{3}$ (c), 4 (d), $\mathbf{5}$ (e) $\mathbf{6}$ (f), $\mathbf{7}(\mathrm{g})$ and $\left[\mathrm{Ru}(\mathrm{bpy})_{3}\right] \mathrm{Cl}_{2}(\mathrm{~h})$ at concentration of $10 \mu \mathrm{M}$ upon $650 \mathrm{~nm}$ irradiation. 

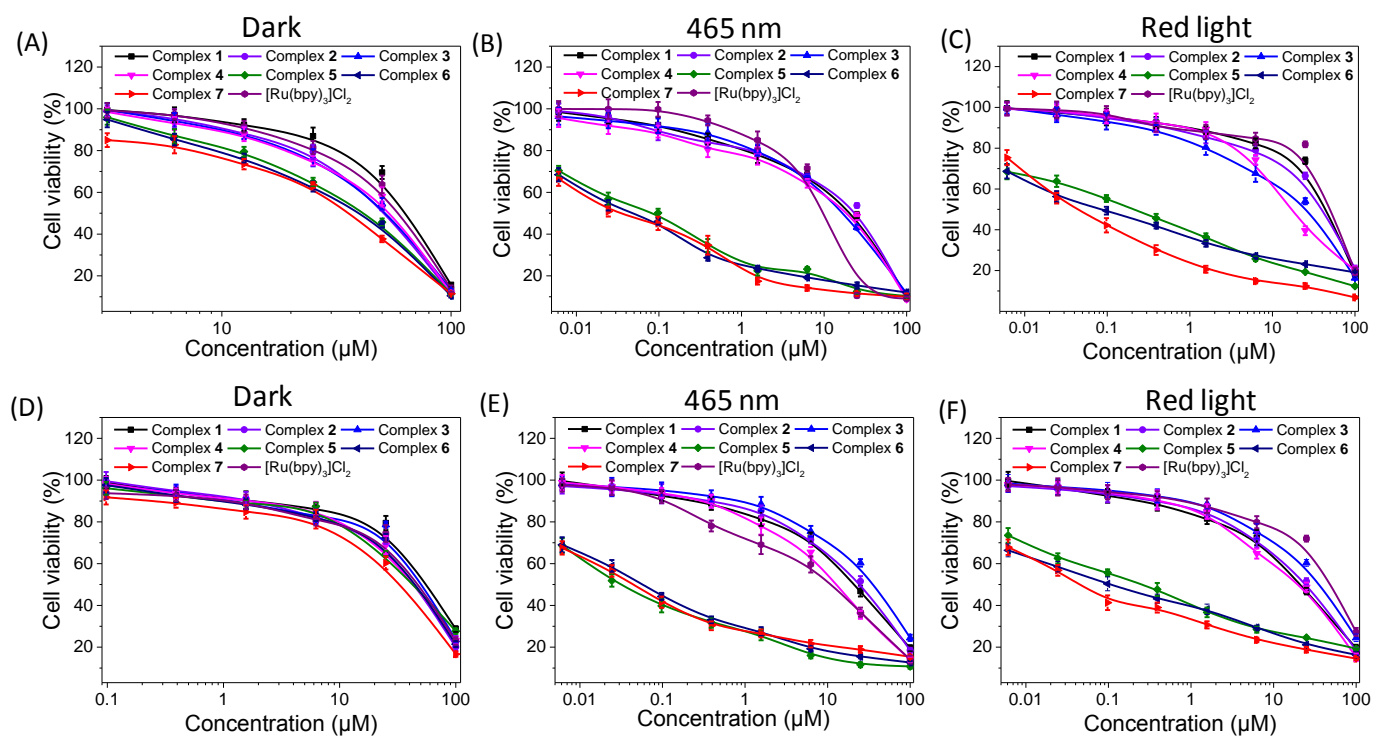

Fig. S32 Dose-dependent drug efficacy for complexes 1-7 and $\left[\mathrm{Ru}(\mathrm{bpy})_{3}\right] \mathrm{Cl}_{2}$ on $A 549(\mathrm{~A}, \mathrm{~B}, \mathrm{C})$ and $\operatorname{HepG}(\mathrm{D}, \mathrm{E}, \mathrm{F})$ cancer cells. Data are expressed as the mean $( \pm S D)$ for three independent experiments. 


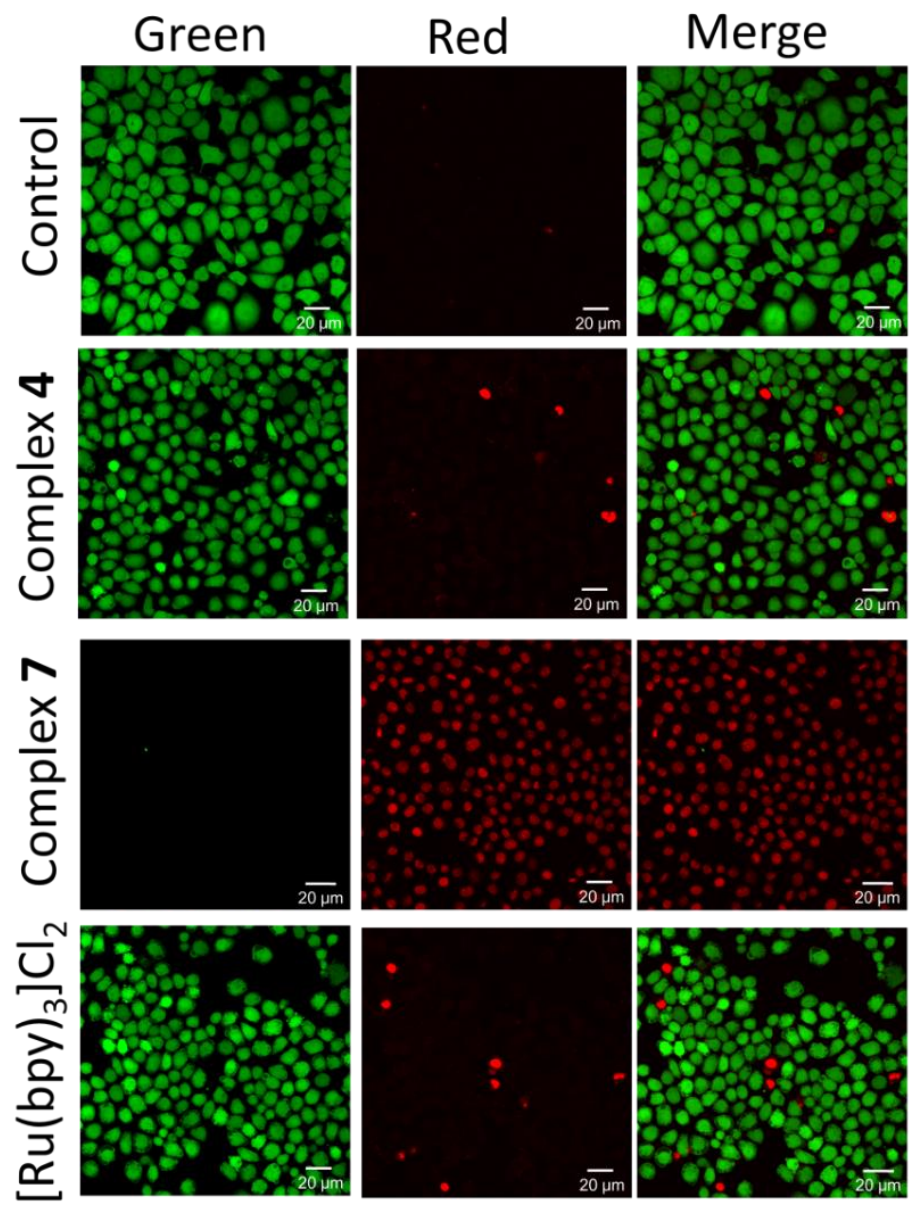

Fig. S33 Confocal fluorescence images of calcein AM (green, live cells)/propidium iodide (PI, red, dead cells) co-stained $\mathrm{A} 549$ cells after treatment with complexes 4,7 and $\left[\mathrm{Ru}(\mathrm{bpy})_{3}\right] \mathrm{Cl}_{2}$ at concentration of $1 \mu \mathrm{M}$ followed by $465 \mathrm{~nm}$ irradiation. 


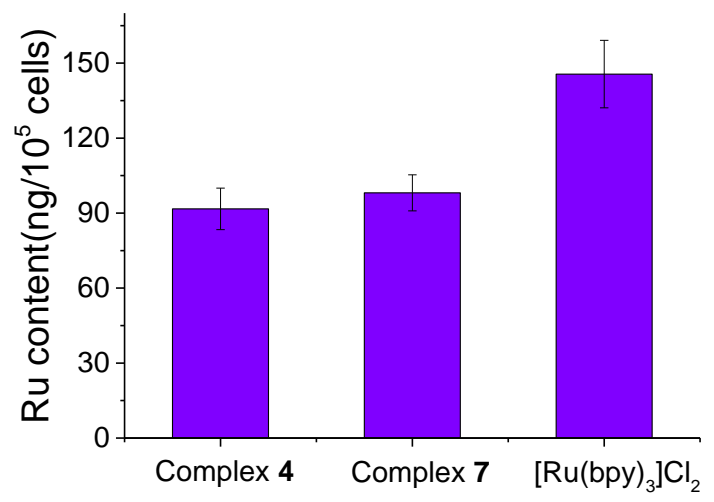

Fig. S34 Intracellular uptake of complexes 4, 7 and $\left[\mathrm{Ru}(\mathrm{bpy})_{3}\right] \mathrm{Cl}_{2}$ (ng/10 5 cells) in A549 cells after a $12 \mathrm{~h}$ incubation.

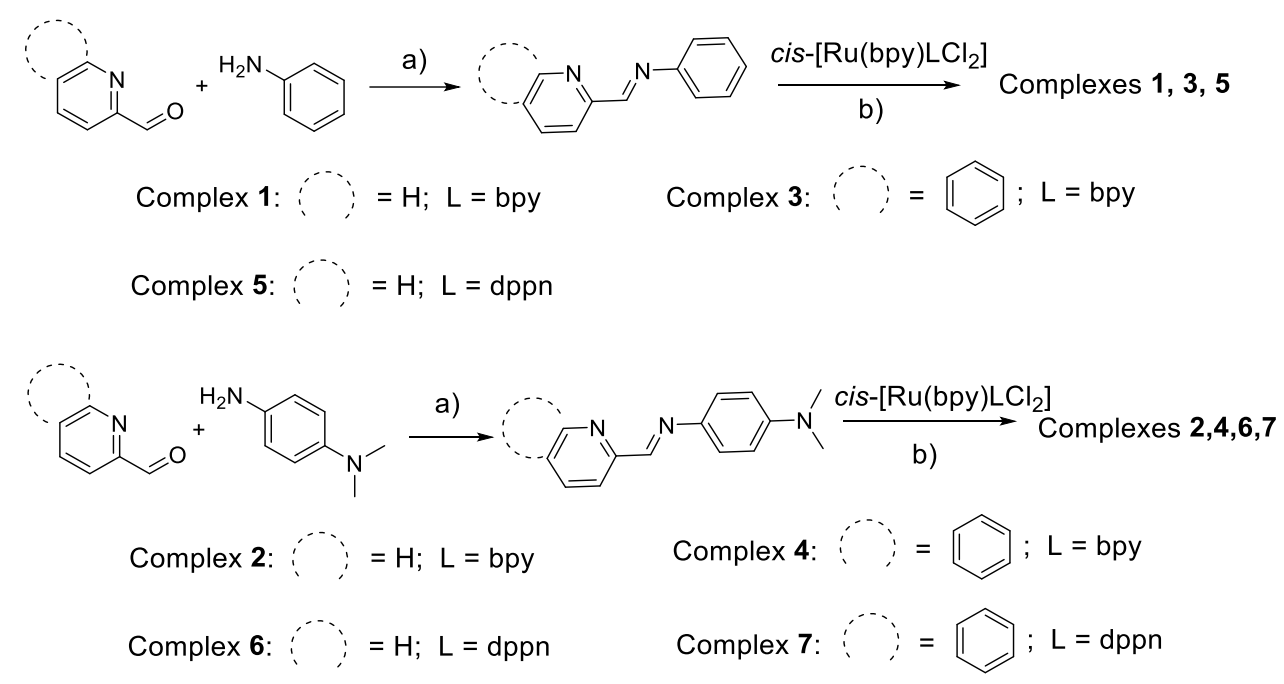

Scheme S1. Preparation of complexes 1-7. Reagents and conditions: a) $\mathrm{CH}_{3} \mathrm{OH}$, reflux, $12 \mathrm{~h}$; b) $\mathrm{CH}_{3} \mathrm{OH}$, reflux, 12 h. 
Table S1. The cartesian coordinates of all optimized structures of complexes 1-7 and $\left[\mathrm{Ru}(\mathrm{bpy})_{3}\right]^{2+}$.

\section{$\left[\mathrm{Ru}(\mathrm{bpy})_{3}\right]^{2+}$}

\begin{tabular}{|c|c|c|c|}
\hline Atom & $x$ & Y & Z \\
\hline $\mathrm{Ru}$ & -0.00126500 & 0.00053700 & 0.00027600 \\
\hline $\mathrm{C}$ & -2.90081000 & 0.22943800 & -0.58371400 \\
\hline $\mathrm{C}$ & -1.89626900 & -1.20976200 & -2.12359800 \\
\hline $\mathrm{C}$ & -3.10669900 & -1.44697000 & -2.76502700 \\
\hline $\mathrm{C}$ & -4.25339400 & -0.81636100 & -2.28540300 \\
\hline $\mathrm{C}$ & -4.14697000 & 0.02868400 & -1.18501100 \\
\hline $\mathrm{C}$ & -2.69019600 & 1. 10993500 & 0.58239500 \\
\hline $\mathrm{C}$ & -1.14352700 & 1. 93681100 & 2. 12388400 \\
\hline $\mathrm{C}$ & -2.11547000 & 2. 69688600 & 2. 76464100 \\
\hline $\mathrm{C}$ & -3.42297500 & 2. 65500300 & 2. 28366400 \\
\hline $\mathrm{C}$ & -3.71036300 & 1. 85373000 & 1. 18293800 \\
\hline $\mathrm{H}$ & -0.98104400 & -1.67728100 & -2.46393400 \\
\hline $\mathrm{H}$ & -3.13895000 & -2.11318000 & -3.61913900 \\
\hline $\mathrm{H}$ & -0.11597200 & 1. 93828700 & 2. 46500100 \\
\hline $\mathrm{H}$ & -1.84328400 & 3. 30506500 & 3. 61929500 \\
\hline $\mathrm{N}$ & -1.41443500 & 1. 15947400 & 1. 05852900 \\
\hline $\mathrm{N}$ & -1.78576600 & -0.39330300 & -1.05881500 \\
\hline $\mathrm{H}$ & -5.21615500 & -0.97794600 & -2.75772900 \\
\hline $\mathrm{H}$ & -4.20828300 & 3. 23553300 & 2. 75524400 \\
\hline $\mathrm{N}$ & -0.29634300 & -1.80249700 & 1. 05921300 \\
\hline $\mathrm{C}$ & 1. 99185800 & -1.03377300 & -2.12586300 \\
\hline
\end{tabular}




\begin{tabular}{|c|c|c|c|}
\hline $\mathrm{C}$ & 2. 79979000 & -1.96371100 & -2.77032600 \\
\hline $\mathrm{C}$ & 2. 82617100 & -3.27283300 & -2.29256100 \\
\hline $\mathrm{C}$ & 2. 04369200 & -3.60376000 & -1.19049400 \\
\hline C & 1. 25049000 & -2.62426200 & -0.58523900 \\
\hline $\mathrm{C}$ & 0.38629900 & -2.88177600 & 0.58378900 \\
\hline $\mathrm{C}$ & 0.25799300 & -4.13598000 & 1. 18812000 \\
\hline $\mathrm{C}$ & -0.57721800 & -4.28764500 & 2. 29069800 \\
\hline $\mathrm{C}$ & -1.27050500 & -3.17747400 & 2. 76979500 \\
\hline $\mathrm{C}$ & -1.10300600 & -1.95664200 & 2. 12606400 \\
\hline $\mathrm{H}$ & 1.93849900 & -0.00703900 & -2.46522400 \\
\hline $\mathrm{H}$ & 3. 44461100 & -4.02607500 & -2.76823400 \\
\hline $\mathrm{H}$ & 2. 05339600 & -4.61581300 & -0.80684200 \\
\hline $\mathrm{H}$ & 0.80297500 & -4.98825000 & 0.80337300 \\
\hline $\mathrm{H}$ & -0.68270500 & -5.25692900 & 2. 76552400 \\
\hline $\mathrm{H}$ & -1.93157200 & -3.24581400 & 3. 62579200 \\
\hline $\mathrm{H}$ & -1.61958000 & -1.06815300 & 2. 46672100 \\
\hline $\mathrm{H}$ & 3. 39079700 & -1.65851200 & -3.62588800 \\
\hline $\mathrm{N}$ & 0.55352400 & 1. 74113500 & -1.05958600 \\
\hline $\mathrm{C}$ & 2. 24101900 & 0.02185000 & 2. 12964000 \\
\hline $\mathrm{C}$ & 3. 38422600 & 0.48292500 & 2. 77248800 \\
\hline $\mathrm{C}$ & 4. 00465600 & 1. 63442300 & 2. 29106800 \\
\hline $\mathrm{C}$ & 3. 45830500 & 2. 28316700 & 1. 18789400 \\
\hline $\mathrm{C}$ & 2. 30482300 & 1. 77215100 & 0.58513000 \\
\hline $\mathrm{C}$ & 1. 65130200 & 2. 39354400 & -0.58397000 \\
\hline
\end{tabular}




\begin{tabular}{|c|c|c|c|}
\hline $\mathrm{C}$ & 2. 10494200 & 3.57031300 & -1.18740600 \\
\hline $\mathrm{C}$ & 1. 42950900 & 4. 08424800 & -2.29008400 \\
\hline $\mathrm{C}$ & 0.30905400 & 3. 40845500 & -2.77016400 \\
\hline $\mathrm{C}$ & -0.09510900 & 2.24413700 & -2.12679400 \\
\hline $\mathrm{H}$ & 1. 72593500 & -0.86688700 & 2. 47154600 \\
\hline $\mathrm{H}$ & 4. 89932000 & 2. 02348200 & 2. 76468000 \\
\hline $\mathrm{H}$ & 3. 92902500 & 3. 17783700 & 0.80130600 \\
\hline $\mathrm{H}$ & 2. 97595300 & 4. 08396400 & -0.80160400 \\
\hline $\mathrm{H}$ & 1. 77441800 & 4. 99667700 & -2.76400900 \\
\hline $\mathrm{H}$ & -0.24881700 & 3. 76911900 & -3.62637600 \\
\hline $\mathrm{H}$ & -0.95812600 & 1. 68642700 & -2.46803600 \\
\hline $\mathrm{H}$ & 3. 77151400 & -0.05605100 & 3. 62916600 \\
\hline $\mathrm{N}$ & 1. 23196300 & -1.34700300 & -1.05946600 \\
\hline $\mathrm{N}$ & 1. 70714400 & 0.64410300 & 1. 06167900 \\
\hline $\mathrm{H}$ & -4.72026300 & 1. 81176100 & 0.79612500 \\
\hline $\mathrm{H}$ & -5.02833300 & 0.52427400 & -0.79909300 \\
\hline
\end{tabular}

$[1]^{2+}$

\begin{tabular}{lccc}
\hline Atom & $\mathrm{X}$ & $\mathrm{Y}$ & $\mathrm{Z}$ \\
\hline $\mathrm{C}$ & -1.85506300 & -1.14823500 & 1.73932100 \\
$\mathrm{C}$ & -1.00713600 & 0.72589600 & 2.84561800 \\
$\mathrm{C}$ & -1.89887700 & 0.56682500 & 3.90053700 \\
$\mathrm{C}$ & -2.80239200 & -0.49346200 & 3.85841500 \\
\hline
\end{tabular}




\begin{tabular}{|c|c|c|c|}
\hline $\mathrm{C}$ & -2.77804900 & -1.35774000 & 2. 76786100 \\
\hline $\mathrm{C}$ & -1.73946400 & -2.01917600 & 0.55324700 \\
\hline $\mathrm{C}$ & -0.61747000 & -2.40620300 & -1.45504600 \\
\hline $\mathrm{C}$ & -1.35264500 & -3.56023200 & -1.70078900 \\
\hline $\mathrm{C}$ & -2.32171500 & -3.94551900 & -0.77645300 \\
\hline $\mathrm{C}$ & -2.51339800 & -3.16767200 & 0.36120500 \\
\hline $\mathrm{H}$ & -0.28806500 & 1. 53523400 & 2. 83624900 \\
\hline $\mathrm{H}$ & -1.87842300 & 1. 26410700 & 4. 72983900 \\
\hline $\mathrm{H}$ & 0.14182500 & -2.06969400 & -2.14960700 \\
\hline $\mathrm{H}$ & -1.16222900 & -4.13561800 & -2.59913500 \\
\hline $\mathrm{N}$ & -0.80302900 & -1.64474500 & -0.36144100 \\
\hline $\mathrm{N}$ & -0.97996400 & -0.10555900 & 1. 78741400 \\
\hline $\mathrm{H}$ & -3.51575800 & -0.64840900 & 4. 66039700 \\
\hline $\mathrm{H}$ & -2.91680300 & -4.83843600 & -0.93359300 \\
\hline $\mathrm{N}$ & 1. 83354500 & -1.15546200 & 0.80205900 \\
\hline $\mathrm{C}$ & 1. 44073200 & 0.74714300 & -2.68547900 \\
\hline $\mathrm{C}$ & 2. 35920900 & 0.70100100 & -3.72815200 \\
\hline $\mathrm{C}$ & 3. 50168700 & -0.08299500 & -3.57890600 \\
\hline $\mathrm{C}$ & 3. 68595000 & -0.78721300 & -2.39279700 \\
\hline C & 2. 72530100 & -0.70207800 & -1.38071400 \\
\hline $\mathrm{C}$ & 2. 83866300 & -1.39991400 & -0.08482300 \\
\hline C & 3. 89674800 & -2.25124400 & 0.24679600 \\
\hline $\mathrm{C}$ & 3. 92883500 & -2.85413100 & 1. 50060500 \\
\hline C & 2. 89863600 & -2.59289800 & 2. 40221700 \\
\hline
\end{tabular}




\begin{tabular}{|c|c|c|c|}
\hline $\mathrm{C}$ & 1. 87072800 & -1.74138400 & 2. 01343500 \\
\hline $\mathrm{H}$ & 0.54213700 & 1. 34693700 & -2.75657400 \\
\hline $\mathrm{H}$ & 4. 24157000 & -0.14410200 & -4.36941300 \\
\hline $\mathrm{H}$ & 4. 57284200 & -1.39272500 & -2.25816700 \\
\hline $\mathrm{H}$ & 4. 68856100 & -2.44547000 & -0.46502800 \\
\hline $\mathrm{H}$ & 4. 74594300 & -3.51586800 & 1. 76610400 \\
\hline $\mathrm{H}$ & 2. 88115500 & -3.03756600 & 3. 39027700 \\
\hline $\mathrm{H}$ & 1. 05025400 & -1.51076000 & 2. 68087100 \\
\hline $\mathrm{H}$ & 2. 17412800 & 1. 27134400 & -4.63080400 \\
\hline $\mathrm{H}$ & -3.47356600 & -2.18559100 & 2. 72040100 \\
\hline $\mathrm{H}$ & -3.25555500 & -3.45749500 & 1.09380700 \\
\hline $\mathrm{N}$ & 1.60709200 & 0.05988700 & -1.53976700 \\
\hline $\mathrm{C}$ & 2. 36298500 & 2. 10524100 & 1. 31004200 \\
\hline $\mathrm{C}$ & 2. 87333400 & 3. 36921800 & 1. 60724100 \\
\hline $\mathrm{C}$ & 2. 15167000 & 4. 50204700 & 1. 23454400 \\
\hline $\mathrm{C}$ & 0.93642200 & 4. 33339100 & 0.57410900 \\
\hline $\mathrm{C}$ & 0.48456600 & 3. 03973100 & 0.30681900 \\
\hline $\mathrm{C}$ & -0.77227200 & 2. 77190000 & -0.36877500 \\
\hline $\mathrm{C}$ & -2.38639700 & 1. 28860800 & -1.19239100 \\
\hline $\mathrm{C}$ & -4.78270600 & 1. 62387100 & -1.20720900 \\
\hline $\mathrm{C}$ & -4.89348100 & 0.79439900 & -2.32496700 \\
\hline $\mathrm{C}$ & -3.74778400 & 0.20938400 & -2.87199100 \\
\hline $\mathrm{N}$ & 1. 19319600 & 1. 93246500 & 0.67394300 \\
\hline $\mathrm{N}$ & -1.10126000 & 1. 54118800 & -0.61697900 \\
\hline
\end{tabular}




\begin{tabular}{lrrr}
\hline $\mathrm{H}$ & 2.52602900 & 5.49588600 & 1.45347800 \\
$\mathrm{H}$ & 0.33874400 & 5.18379600 & 0.26610100 \\
$\mathrm{H}$ & -1.41275200 & 3.60206300 & -0.66080700 \\
$\mathrm{H}$ & -5.66858900 & 2.07305300 & -0.76935200 \\
$\mathrm{H}$ & -3.82624700 & -0.43308100 & -3.74337900 \\
$\mathrm{C}$ & -3.53352200 & 1.87665400 & -0.63973000 \\
$\mathrm{H}$ & -3.44806500 & 2.50251400 & 0.24275800 \\
$\mathrm{C}$ & -2.49661500 & 0.44362900 & -2.30420000 \\
$\mathrm{H}$ & -1.60876600 & -0.00433300 & -2.73394500 \\
$\mathrm{Ru}$ & 0.28888100 & 0.09910900 & 0.11107200 \\
$\mathrm{H}$ & -5.86659700 & 0.59989400 & -2.76465000 \\
$\mathrm{H}$ & 2.89858000 & 1.20634400 & 1.58946200 \\
$\mathrm{H}$ & & & \\
\hline
\end{tabular}

$[2]^{2+}$

\begin{tabular}{lccc}
\hline Atom & $X$ & $Y$ & $Z$ \\
\hline C & -0.70198500 & -1.11722400 & 2.32706600 \\
C & 0.29745400 & 0.86335500 & 3.05564700 \\
C & -0.26885500 & 0.74135800 & 4.31960500 \\
C & -1.08580900 & -0.35646800 & 4.58355200 \\
C & -1.30184500 & -1.29341300 & 3.57749500 \\
C & -0.85220800 & -2.06730100 & 1.20739200 \\
C & -0.27459400 & -2.55797400 & -0.99850700 \\
\hline
\end{tabular}




\begin{tabular}{|c|c|c|c|}
\hline $\mathrm{C}$ & -0.96374200 & -3.76464100 & -0.96362200 \\
\hline $\mathrm{C}$ & -1.62824100 & -4.12143200 & 0.20848400 \\
\hline $\mathrm{C}$ & -1.56794000 & -3.26490200 & 1. 30312100 \\
\hline $\mathrm{H}$ & 0.93910100 & 1. 69943700 & 2. 80785300 \\
\hline $\mathrm{H}$ & -0.06905000 & 1. 49542600 & 5. 07182600 \\
\hline $\mathrm{H}$ & 0.24816500 & -2.23912400 & -1.89167600 \\
\hline $\mathrm{H}$ & -0.97493500 & -4.40125200 & -1.84053000 \\
\hline $\mathrm{N}$ & -0.22167500 & -1.71901700 & 0.05240100 \\
\hline $\mathrm{N}$ & 0.09078700 & -0.03803400 & 2. 07736700 \\
\hline $\mathrm{H}$ & -1.54808500 & -0.48466400 & 5. 55618100 \\
\hline $\mathrm{H}$ & -2.18002800 & -5.05275500 & 0.27411700 \\
\hline $\mathrm{N}$ & 2. 58935400 & -1.02700200 & 0.38843900 \\
\hline $\mathrm{C}$ & 1. 10177600 & 0.62385000 & -2.92752500 \\
\hline $\mathrm{C}$ & 1. 69160600 & 0.55997500 & -4.18498100 \\
\hline $\mathrm{C}$ & 2. 88523800 & -0.14499400 & -4.32982500 \\
\hline $\mathrm{C}$ & 3. 44637700 & -0.75769700 & -3.21332100 \\
\hline $\mathrm{C}$ & 2. 80484000 & -0.65967900 & -1.97507200 \\
\hline $\mathrm{C}$ & 3. 32446600 & -1.26674600 & -0.73371600 \\
\hline $\mathrm{C}$ & 4. 49148700 & -2.03424100 & -0.67678000 \\
\hline $\mathrm{C}$ & 4. 91259200 & -2.55850000 & 0.54154700 \\
\hline C & 4. 15514400 & -2.30466600 & 1. 68373800 \\
\hline $\mathrm{C}$ & 3. 00161500 & -1.53796400 & 1. 56366000 \\
\hline $\mathrm{H}$ & 0.17687400 & 1. 16354800 & -2.76692500 \\
\hline $\mathrm{H}$ & 3. 37564100 & -0.21580900 & -5.29448900 \\
\hline
\end{tabular}




\begin{tabular}{|c|c|c|c|}
\hline $\mathrm{H}$ & 4. 37684700 & -1.30254200 & -3.30780900 \\
\hline $\mathrm{H}$ & 5. 06676300 & -2.22441200 & -1.57362600 \\
\hline $\mathrm{H}$ & 5. 81655200 & -3.15522200 & 0.59497500 \\
\hline $\mathrm{H}$ & 4. 44300800 & -2.69128800 & 2. 65435500 \\
\hline $\mathrm{H}$ & 2. 38223700 & -1.31727000 & 2. 42372900 \\
\hline $\mathrm{H}$ & 1. 21889700 & 1. 05626700 & -5.02441000 \\
\hline $\mathrm{H}$ & -1.93340300 & -2.15152800 & 3. 76751600 \\
\hline $\mathrm{H}$ & -2.06929700 & -3.53221200 & 2. 22426400 \\
\hline $\mathrm{N}$ & 1. 63523500 & 0.02681800 & -1.84517300 \\
\hline $\mathrm{C}$ & 3. 05765100 & 2.24703800 & 0.58528300 \\
\hline $\mathrm{C}$ & 3. 56760500 & 3.54082100 & 0.67916900 \\
\hline $\mathrm{C}$ & 2. 71158200 & 4. 62537600 & 0.48479700 \\
\hline $\mathrm{C}$ & 1. 37085800 & 4. 37886500 & 0.20327800 \\
\hline $\mathrm{C}$ & 0.92405000 & 3. 05614800 & 0.12282300 \\
\hline $\mathrm{C}$ & -0.45235400 & 2. 71063600 & -0.16431900 \\
\hline $\mathrm{C}$ & -2.15688000 & 1. 12993800 & -0.44138300 \\
\hline $\mathrm{C}$ & -4.50640700 & 1. 50807700 & 0.06215200 \\
\hline $\mathrm{C}$ & -4.90336800 & 0.48847700 & -0.84404900 \\
\hline $\mathrm{C}$ & -3.87023800 & -0.20591000 & -1.52949700 \\
\hline $\mathrm{N}$ & 1. 76545700 & 1. 99874000 & 0.31446400 \\
\hline $\mathrm{N}$ & -0.78756700 & 1. 45574400 & -0.26731200 \\
\hline $\mathrm{H}$ & 3. 08159600 & 5.64261400 & 0.55164900 \\
\hline $\mathrm{H}$ & 0.66916100 & 5. 19026100 & 0.04577600 \\
\hline $\mathrm{H}$ & -1.18141500 & 3.50580000 & -0.30447600 \\
\hline
\end{tabular}




\begin{tabular}{|c|c|c|c|}
\hline $\mathrm{H}$ & -5.24733200 & 2. 04701300 & 0.63842900 \\
\hline $\mathrm{H}$ & -4.11348600 & -0.99063000 & -2.23416500 \\
\hline $\mathrm{C}$ & -3.16971400 & 1. 82295700 & 0.24644400 \\
\hline $\mathrm{H}$ & -2.90449400 & 2. 58886500 & 0.96873400 \\
\hline $\mathrm{C}$ & -2.53603800 & 0.10177600 & -1.31887000 \\
\hline $\mathrm{H}$ & -1.77721000 & -0.43697900 & -1.87283000 \\
\hline $\mathrm{N}$ & -6.22453600 & 0.18075000 & -1.04086200 \\
\hline $\mathrm{C}$ & -6.59821100 & -0.91607000 & -1.92507200 \\
\hline $\mathrm{H}$ & -6.17916900 & -1.87271000 & -1.58738900 \\
\hline $\mathrm{H}$ & -7.68345400 & -1.00848000 & -1.93981100 \\
\hline $\mathrm{H}$ & -6.25993700 & -0.73905000 & -2.95349400 \\
\hline $\mathrm{C}$ & -7.26173100 & 0.89743900 & -0.30946800 \\
\hline $\mathrm{H}$ & -7.21903600 & 1. 97545100 & -0.50579700 \\
\hline $\mathrm{H}$ & -8.23817300 & 0.53630400 & -0.62994400 \\
\hline $\mathrm{H}$ & -7.18020000 & 0.74375400 & 0.77470600 \\
\hline $\mathrm{Ru}$ & 0.83767200 & 0.10821800 & 0.10607300 \\
\hline $\mathrm{H}$ & 4. 61872000 & 3. 68337900 & 0.90136700 \\
\hline $\mathrm{H}$ & 3. 69310000 & 1. 38264100 & 0.73391900 \\
\hline
\end{tabular}

$[3]^{2+}$

\begin{tabular}{lccc}
\hline Atom & $\mathrm{X}$ & $\mathrm{Y}$ & $\mathrm{Z}$ \\
\hline $\mathrm{C}$ & 2.05980400 & -0.03284600 & 2.13509700 \\
\hline
\end{tabular}




\begin{tabular}{|c|c|c|c|}
\hline $\mathrm{C}$ & 0.33568100 & -1.53776100 & 2. 60414400 \\
\hline $\mathrm{C}$ & 0.95618000 & -1.95584500 & 3. 77634700 \\
\hline $\mathrm{C}$ & 2. 17850000 & -1.38553800 & 4. 12717300 \\
\hline C & 2. 73368200 & -0.41488500 & 3. 29821800 \\
\hline $\mathrm{C}$ & 2. 55112400 & 1. 00120300 & 1. 20352800 \\
\hline $\mathrm{C}$ & 2. 12908800 & 2. 18567600 & -0.76343900 \\
\hline $\mathrm{C}$ & 3. 28912000 & 2.93783100 & -0.61695700 \\
\hline $\mathrm{C}$ & 4. 10758800 & 2. 69789000 & 0.48489700 \\
\hline $\mathrm{C}$ & 3. 73193200 & 1. 72199900 & 1. 40296200 \\
\hline $\mathrm{H}$ & -0.61374900 & -1.95257800 & 2. 29024000 \\
\hline $\mathrm{H}$ & 0.48449300 & -2.71275800 & 4. 39187800 \\
\hline $\mathrm{H}$ & 1. 46730200 & 2. 33795100 & -1.60667000 \\
\hline $\mathrm{H}$ & 3. 53578000 & 3. 69085200 & -1.35613600 \\
\hline $\mathrm{N}$ & 1. 76490500 & 1. 23487800 & 0.11597900 \\
\hline $\mathrm{N}$ & 0.86853700 & -0.60039500 & 1. 79897800 \\
\hline $\mathrm{H}$ & 2. 69393300 & -1.68840600 & 5. 03196400 \\
\hline $\mathrm{H}$ & 5. 02170700 & 3. 26237400 & 0.63263800 \\
\hline $\mathrm{N}$ & -0.91729100 & 1. 79993600 & 0.77804100 \\
\hline $\mathrm{C}$ & -0.78133400 & 0.44048200 & -2.97700000 \\
\hline $\mathrm{C}$ & -1.39486400 & 1. 04998800 & -4.06554400 \\
\hline $\mathrm{C}$ & -2.07218400 & 2. 25139500 & -3.86584700 \\
\hline $\mathrm{C}$ & -2.11130000 & 2. 79787300 & -2.58667100 \\
\hline $\mathrm{C}$ & -1.47121900 & 2. 13911500 & -1.53281800 \\
\hline $\mathrm{C}$ & -1.46586600 & 2. 63796900 & -0.14419100 \\
\hline
\end{tabular}




\begin{tabular}{|c|c|c|c|}
\hline $\mathrm{C}$ & -1.98343800 & 3. 88114700 & 0.23168400 \\
\hline $\mathrm{C}$ & -1.94324400 & 4. 26853800 & 1. 56747300 \\
\hline $\mathrm{C}$ & -1.38316500 & 3. 40205000 & 2. 50492000 \\
\hline $\mathrm{C}$ & -0.88005300 & 2. 18171700 & 2. 06898600 \\
\hline $\mathrm{H}$ & -0.24724900 & -0.49451200 & -3.08790600 \\
\hline $\mathrm{H}$ & -2.56668900 & 2. 75481900 & -4.68930400 \\
\hline $\mathrm{H}$ & -2.64421800 & 3. 72358300 & -2.41128700 \\
\hline $\mathrm{H}$ & -2.40579300 & 4. 54554400 & -0.51101100 \\
\hline $\mathrm{H}$ & -2.34130000 & 5. 23144300 & 1. 86821500 \\
\hline $\mathrm{H}$ & -1.33077200 & 3. 65845000 & 3. 55651400 \\
\hline $\mathrm{H}$ & -0.44288100 & 1. 47569000 & 2. 76379800 \\
\hline $\mathrm{H}$ & -1.33861200 & 0.58408500 & -5.04231500 \\
\hline $\mathrm{H}$ & 3. 68200900 & 0.03760300 & 3. 55744600 \\
\hline $\mathrm{H}$ & 4. 35164400 & 1. 52977200 & 2. 26924500 \\
\hline $\mathrm{N}$ & -0.81031300 & 0.96549400 & -1.73780000 \\
\hline $\mathrm{C}$ & -2.91089300 & -1.39260000 & 0.27842500 \\
\hline $\mathrm{C}$ & -3.81844200 & -2.47643700 & 0.00788700 \\
\hline $\mathrm{C}$ & -3.33407000 & -3.61746800 & -0.67173600 \\
\hline $\mathrm{C}$ & -2.01441800 & -3.66539000 & -1.04287500 \\
\hline $\mathrm{C}$ & -1.17937800 & -2.56147000 & -0.75768000 \\
\hline $\mathrm{C}$ & 0.21856600 & -2.60847300 & -1.14167200 \\
\hline C & 2. 36308400 & -1.69057500 & -1.24890400 \\
\hline $\mathrm{C}$ & 4. 47851900 & -2.81880600 & -0.93552000 \\
\hline $\mathrm{C}$ & 5. 07955600 & -1.94379900 & -1.84215400 \\
\hline
\end{tabular}




\begin{tabular}{|c|c|c|c|}
\hline $\mathrm{C}$ & 4. 31764600 & -0.94283100 & -2.45203100 \\
\hline $\mathrm{N}$ & -1.59714100 & -1.44267500 & -0.13121900 \\
\hline $\mathrm{N}$ & 0.96694200 & -1.57027900 & -0.94392600 \\
\hline $\mathrm{H}$ & -4.00652400 & -4.44263400 & -0.88365500 \\
\hline $\mathrm{H}$ & -1.59703200 & -4.52550400 & -1.55341300 \\
\hline $\mathrm{H}$ & 0.61742300 & -3.51380100 & -1.59547400 \\
\hline $\mathrm{H}$ & 5. 06389100 & -3.59622700 & -0.45466500 \\
\hline $\mathrm{H}$ & 4. 77740900 & -0.26574400 & -3.16507900 \\
\hline $\mathrm{C}$ & 3. 11987600 & -2.69976900 & -0.63898500 \\
\hline $\mathrm{H}$ & 2. 64913900 & -3.36866700 & 0.07434800 \\
\hline $\mathrm{C}$ & 2. 96298100 & -0.80568200 & -2.15268500 \\
\hline $\mathrm{H}$ & 2. 36978100 & -0.03776600 & -2.63489900 \\
\hline C & -5.16809700 & -2.38273000 & 0.43640400 \\
\hline C & -5.61208500 & -1.27468200 & 1. 11973400 \\
\hline C & -4.71468000 & -0.21754800 & 1. 40480700 \\
\hline C & -3.40054300 & -0.27210400 & 0.99573400 \\
\hline $\mathrm{H}$ & -5.83818000 & -3.20839200 & 0.21736800 \\
\hline $\mathrm{H}$ & -6.64451300 & -1.20958000 & 1. 44705200 \\
\hline $\mathrm{H}$ & -5.06586400 & 0.64887900 & 1. 95619600 \\
\hline $\mathrm{H}$ & -2.72158100 & 0.53167900 & 1. 22710900 \\
\hline $\mathrm{Ru}$ & 0.02689000 & 0.06701900 & -0.01477500 \\
\hline $\mathrm{H}$ & 6. 13588800 & -2.03949000 & -2.07270800 \\
\hline
\end{tabular}




\section{$[4]^{2+}$}

\begin{tabular}{|c|c|c|c|}
\hline Atom & $x$ & Y & Z \\
\hline $\mathrm{C}$ & 1.13399500 & 0.56991900 & 2.48142800 \\
\hline $\mathrm{C}$ & -0.33643700 & -1.21226100 & 2. 82417800 \\
\hline $\mathrm{C}$ & 0.16399300 & -1.44101000 & 4. 10141600 \\
\hline $\mathrm{C}$ & 1. 19412700 & -0.62887000 & 4. 57232200 \\
\hline $\mathrm{C}$ & 1. 68144000 & 0.38631100 & 3. 75417100 \\
\hline $\mathrm{C}$ & 1. 55888300 & 1. 63386900 & 1. 55101700 \\
\hline $\mathrm{C}$ & 1. 22524100 & 2. 61739000 & -0.53878800 \\
\hline $\mathrm{C}$ & 2. 16833600 & 3. 60519300 & -0.28002100 \\
\hline $\mathrm{C}$ & 2. 83428600 & 3. 58965300 & 0.94398500 \\
\hline $\mathrm{C}$ & 2. 52238600 & 2. 59635700 & 1. 86703000 \\
\hline $\mathrm{H}$ & -1.13440100 & -1.81814900 & 2. 41419300 \\
\hline $\mathrm{H}$ & -0.24937300 & -2.24125700 & 4. 70396500 \\
\hline $\mathrm{H}$ & 0.69144500 & 2. 58898900 & -1.48035600 \\
\hline $\mathrm{H}$ & 2. 36961700 & 4. 36259400 & -1.02841400 \\
\hline $\mathrm{N}$ & 0.92866600 & 1. 64595900 & 0.34379900 \\
\hline $\mathrm{N}$ & 0.13266700 & -0.23386200 & 2. 02812200 \\
\hline $\mathrm{H}$ & 1. 61314900 & -0.77959000 & 5. 56115300 \\
\hline $\mathrm{H}$ & 3. 57960500 & 4. 34073300 & 1. 18157000 \\
\hline $\mathrm{N}$ & -1.87242800 & 1. 69948200 & 0.49792600 \\
\hline $\mathrm{C}$ & -0.81152600 & 0.12939000 & -3.01882000 \\
\hline $\mathrm{C}$ & -1.31327200 & 0.52904900 & -4.25230900 \\
\hline $\mathrm{C}$ & -2.22172200 & 1. 58514900 & -4.29582000 \\
\hline
\end{tabular}




\begin{tabular}{|c|c|c|c|}
\hline $\mathrm{C}$ & -2.59652500 & 2. 20089100 & -3.10541400 \\
\hline $\mathrm{C}$ & -2.05562300 & 1. 75516200 & -1.89574800 \\
\hline $\mathrm{C}$ & -2.39653900 & 2. 33998500 & -0.58397300 \\
\hline $\mathrm{C}$ & -3.20191600 & 3. 47229500 & -0.42776500 \\
\hline $\mathrm{C}$ & -3.47312200 & 3. 95398700 & 0.84916700 \\
\hline $\mathrm{C}$ & -2.92896900 & 3. 29356500 & 1. 94972500 \\
\hline $\mathrm{C}$ & -2.13368100 & 2. 17470500 & 1. 73056000 \\
\hline $\mathrm{H}$ & -0.10538100 & -0.68756100 & -2.93854300 \\
\hline $\mathrm{H}$ & -2.63686800 & 1. 92354200 & -5.23882600 \\
\hline $\mathrm{H}$ & -3.30980600 & 3. 01495300 & -3.12029200 \\
\hline $\mathrm{H}$ & -3.60896700 & 3. 97910400 & -1.29309200 \\
\hline $\mathrm{H}$ & -4.09642000 & 4. 83177500 & 0.97974700 \\
\hline $\mathrm{H}$ & -3.11061200 & 3. 63192200 & 2. 96307900 \\
\hline $\mathrm{H}$ & -1.69568600 & 1. 62759700 & 2. 55606200 \\
\hline $\mathrm{H}$ & -0.99375100 & 0.01656000 & -5.15211500 \\
\hline $\mathrm{H}$ & 2. 48047700 & 1. 02583800 & 4. 10622000 \\
\hline $\mathrm{H}$ & 3. 02027300 & 2. 57790300 & 2. 82780400 \\
\hline $\mathrm{N}$ & -1.16475500 & 0.72456400 & -1.86401500 \\
\hline $\mathrm{C}$ & -3.14209600 & -1.83607400 & 0.04559600 \\
\hline $\mathrm{C}$ & -3.77139300 & -3.10575400 & -0.20246500 \\
\hline C & -2.96834600 & -4.19456400 & -0.61685400 \\
\hline $\mathrm{C}$ & -1.61815200 & -4.01262600 & -0.76157500 \\
\hline $\mathrm{C}$ & -1.06145600 & -2.73486400 & -0.51354300 \\
\hline $\mathrm{C}$ & 0.36190000 & -2.54206400 & -0.68195600 \\
\hline
\end{tabular}




\begin{tabular}{|c|c|c|c|}
\hline $\mathrm{C}$ & 2. 29070200 & -1.23141800 & -0.61527900 \\
\hline $\mathrm{C}$ & 4. 51700400 & -2.03050100 & -0.05352500 \\
\hline $\mathrm{C}$ & 5. 12002400 & -1.00890400 & -0.83435400 \\
\hline C & 4. 25000800 & -0.10096800 & -1.49672500 \\
\hline $\mathrm{N}$ & -1.78590800 & -1.66246200 & -0.13274300 \\
\hline $\mathrm{N}$ & 0.87748000 & -1.35826500 & -0.53289900 \\
\hline $\mathrm{H}$ & -3.42795200 & -5.15917200 & -0.80812800 \\
\hline $\mathrm{H}$ & -0.96480700 & -4.82162000 & -1.06739900 \\
\hline $\mathrm{H}$ & 0.98144100 & -3.39333000 & -0.95577000 \\
\hline $\mathrm{H}$ & 5. 12963000 & -2.73568000 & 0.49323300 \\
\hline $\mathrm{H}$ & 4. 65402800 & 0.68981600 & -2.11552800 \\
\hline $\mathrm{C}$ & 3. 13831000 & -2.14133700 & 0.04001500 \\
\hline $\mathrm{H}$ & 2. 71128300 & -2.92122400 & 0.66315400 \\
\hline $\mathrm{C}$ & 2. 87392200 & -0.20625300 & -1.37519900 \\
\hline $\mathrm{H}$ & 2. 24094200 & 0.48875000 & -1.91332100 \\
\hline $\mathrm{C}$ & -5.17123200 & -3.24312600 & -0.01773000 \\
\hline $\mathrm{C}$ & -5.93231400 & -2.17889000 & 0.40824900 \\
\hline $\mathrm{C}$ & -5.31200600 & -0.93492700 & 0.67101100 \\
\hline $\mathrm{C}$ & -3.95561900 & -0.76607100 & 0.49494300 \\
\hline $\mathrm{H}$ & -5.62605600 & -4.20907200 & -0.21519400 \\
\hline $\mathrm{H}$ & -7.00231500 & -2.29073800 & 0.54936400 \\
\hline $\mathrm{H}$ & -5.91165800 & -0.09969400 & 1. 01890400 \\
\hline $\mathrm{H}$ & -3.49233600 & 0. 18208400 & 0.70910100 \\
\hline $\mathrm{N}$ & 6. 48247500 & -0.89865100 & -0.93953800 \\
\hline
\end{tabular}




\begin{tabular}{llll}
\hline $\mathrm{C}$ & 7.07374800 & 0.18276600 & -1.71731400 \\
$\mathrm{H}$ & 6.78359000 & 1.16758700 & -1.32967900 \\
$\mathrm{H}$ & 8.15916000 & 0.10643600 & -1.66636200 \\
$\mathrm{H}$ & 6.77974000 & 0.13119400 & -2.77323900 \\
$\mathrm{C}$ & 7.34985800 & -1.84602500 & -0.25112800 \\
$\mathrm{H}$ & 7.16242600 & -2.87629600 & -0.57800500 \\
$\mathrm{H}$ & 8.38861300 & -1.60575600 & -0.47414800 \\
$\mathrm{H}$ & 7.21719800 & -1.80375100 & 0.83774700 \\
$\mathrm{Ru}$ & -0.50274800 & 0.13689500 & 0.05198900 \\
\hline
\end{tabular}

$[5]^{2+}$

\begin{tabular}{lccc}
\hline Atom & $X$ & $Y$ & $Z$ \\
\hline C & 3.81042900 & -1.61661000 & -1.50507100 \\
C & 3.98816500 & 0.49690400 & -2.48429300 \\
C & 4.99048500 & 0.06624200 & -3.34625600 \\
C & 5.41287100 & -1.25972700 & -3.27183300 \\
C & 4.81590300 & -2.10703900 & -2.34309500 \\
C & 3.10641300 & -2.43980500 & -0.50247500 \\
C & 1.46284200 & -2.47873400 & 1.15260300 \\
C & 1.65645100 & -3.83608200 & 1.38251500 \\
C & 2.62217300 & -4.50963900 & 0.63720600 \\
C & 3.35065200 & -3.80352100 & -0.31502400 \\
H & 3.62849800 & 1.51779100 & -2.50803800 \\
\hline
\end{tabular}




\begin{tabular}{|c|c|c|c|}
\hline $\mathrm{H}$ & 5. 42372400 & 0.76248100 & -4.05463300 \\
\hline $\mathrm{H}$ & 0.72510500 & -1.91833100 & 1. 71281600 \\
\hline $\mathrm{H}$ & 1. 05951700 & -4.34311700 & 2. 13144600 \\
\hline $\mathrm{N}$ & 2. 16987400 & -1.78762500 & 0.24001800 \\
\hline $\mathrm{N}$ & 3. 40772900 & -0.31766200 & -1.58341300 \\
\hline $\mathrm{H}$ & 6. 19392900 & -1.63176000 & -3.92574300 \\
\hline $\mathrm{H}$ & 2. 80429300 & -5.56786500 & 0.78889100 \\
\hline $\mathrm{N}$ & 0.26033300 & -0.27031400 & -1.38980100 \\
\hline $\mathrm{C}$ & 0.37553400 & 1. 14583800 & 2. 36496800 \\
\hline $\mathrm{C}$ & -0.76402800 & 1. 38194900 & 3. 13940700 \\
\hline $\mathrm{C}$ & -2.01463800 & 1. 09728900 & 2. 61402100 \\
\hline $\mathrm{C}$ & -2.10730400 & 0.58483000 & 1. 31026500 \\
\hline $\mathrm{C}$ & -0.91658400 & 0.37926500 & 0.59266300 \\
\hline $\mathrm{C}$ & -0.94247100 & -0.13153400 & -0.76569200 \\
\hline $\mathrm{C}$ & -2.15767200 & -0.44913900 & -1.39591400 \\
\hline $\mathrm{C}$ & -2.11381100 & -0.93296800 & -2.71300100 \\
\hline $\mathrm{C}$ & -0.88520900 & -1.07489800 & -3.33882600 \\
\hline $\mathrm{C}$ & 0.28100900 & -0.73364900 & -2.64779900 \\
\hline $\mathrm{H}$ & 1. 36609700 & 1. 35764800 & 2. 74783800 \\
\hline $\mathrm{H}$ & -2.92212400 & 1. 26258200 & 3. 18238500 \\
\hline $\mathrm{H}$ & -3.04076400 & -1.18368500 & -3.21480100 \\
\hline $\mathrm{H}$ & -0.81116100 & -1.44417300 & -4.35493500 \\
\hline $\mathrm{H}$ & 1. 25480600 & -0.82836900 & -3.11174500 \\
\hline $\mathrm{H}$ & -0.65236000 & 1. 78257200 & 4. 14007200 \\
\hline
\end{tabular}




\begin{tabular}{|c|c|c|c|}
\hline $\mathrm{H}$ & 5. 13301500 & -3.13947400 & -2.27371300 \\
\hline $\mathrm{H}$ & 4. 09819100 & -4.31350900 & -0.90862600 \\
\hline $\mathrm{N}$ & 0.30945800 & 0.64843600 & 1. 12141400 \\
\hline C & 1. 08781400 & 2. 96969600 & -1.52105900 \\
\hline $\mathrm{C}$ & 1. 14625200 & 4. 34884400 & -1.72417300 \\
\hline $\mathrm{C}$ & 2. 08579000 & 5. 10291900 & -1.02325800 \\
\hline $\mathrm{C}$ & 2. 94394800 & 4. 45008300 & -0.14048800 \\
\hline $\mathrm{C}$ & 2. 83207400 & 3. 06710600 & 0.01374600 \\
\hline $\mathrm{C}$ & 3. 69421200 & 2. 30285700 & 0.89694300 \\
\hline $\mathrm{C}$ & 4. 42210400 & 0.27070000 & 1. 80316000 \\
\hline $\mathrm{C}$ & 6.69743400 & -0.33419700 & 2. 35957100 \\
\hline $\mathrm{C}$ & 6. 22658900 & -1.20125900 & 3. 34756300 \\
\hline $\mathrm{C}$ & 4. 85092000 & -1.33339400 & 3. 55805100 \\
\hline $\mathrm{N}$ & 1.90824000 & 2. 33199600 & -0.67108200 \\
\hline $\mathrm{N}$ & 3. 49654500 & 1. 02569100 & 1. 01541700 \\
\hline $\mathrm{H}$ & 2. 15088300 & 6. 17643900 & -1.16134800 \\
\hline $\mathrm{H}$ & 3. 69245300 & 4. 99398400 & 0.42468700 \\
\hline $\mathrm{H}$ & 4. 48772800 & 2. 80809600 & 1. 44406400 \\
\hline $\mathrm{H}$ & 7. 76365700 & -0.23407100 & 2. 18236200 \\
\hline $\mathrm{H}$ & 4. 47850600 & -2.00234200 & 4. 32747800 \\
\hline $\mathrm{C}$ & 5. 80120000 & 0.40575500 & 1. 58771800 \\
\hline $\mathrm{H}$ & 6.16333100 & 1. 06371900 & 0.80425600 \\
\hline $\mathrm{C}$ & 3. 94637400 & -0.60974800 & 2. 78290500 \\
\hline $\mathrm{H}$ & 2. 88068100 & -0.70663000 & 2. 95158000 \\
\hline
\end{tabular}




\begin{tabular}{|c|c|c|c|}
\hline $\mathrm{Ru}$ & 1. 92692700 & 0.26335600 & -0.19927500 \\
\hline $\mathrm{C}$ & -3.41599200 & -0.26112700 & -0.66809200 \\
\hline $\mathrm{C}$ & -5.70555400 & -0.38497900 & -0.57804200 \\
\hline $\mathrm{C}$ & -5.68074800 & 0.13917800 & 0.77070700 \\
\hline $\mathrm{C}$ & -3.39107300 & 0.26024800 & 0.68178000 \\
\hline $\mathrm{C}$ & -6.93311100 & -0.70224600 & -1.17530400 \\
\hline $\mathrm{C}$ & -6.88446200 & 0.32467900 & 1. 46414500 \\
\hline $\mathrm{C}$ & -8.10995700 & 0.00802900 & 0.86929600 \\
\hline $\mathrm{C}$ & -8.13486400 & -0.51874200 & -0.48367600 \\
\hline $\mathrm{C}$ & -9.40052800 & -0.83674500 & -1.07272800 \\
\hline $\mathrm{H}$ & -9.41707600 & -1.23099500 & -2.08457600 \\
\hline C & -10.56396700 & -0.64825000 & -0.37572600 \\
\hline $\mathrm{C}$ & -10.53940600 & -0.12987600 & 0.95559100 \\
\hline $\mathrm{C}$ & -9.35190200 & 0.18788600 & 1. 55871000 \\
\hline $\mathrm{H}$ & -6.93169400 & -1.09413700 & -2.18778400 \\
\hline $\mathrm{H}$ & -6.84546900 & 0.71939800 & 2. 47469600 \\
\hline $\mathrm{H}$ & -11.51803200 & -0.89290200 & -0.83238200 \\
\hline $\mathrm{H}$ & -11.47518500 & 0.01049500 & 1. 48777600 \\
\hline $\mathrm{H}$ & -9.33079800 & 0.58163100 & 2. 57074700 \\
\hline $\mathrm{N}$ & -4.49946900 & 0.45160700 & 1. 37057500 \\
\hline $\mathrm{N}$ & -4.54801800 & -0.57131300 & -1.26973200 \\
\hline $\mathrm{H}$ & 0.45965600 & 4. 81165200 & -2.42343800 \\
\hline $\mathrm{H}$ & 0.37062700 & 2. 35627000 & -2.05222200 \\
\hline $\mathrm{H}$ & 6.92622900 & -1.77509400 & 3. 94698700 \\
\hline
\end{tabular}


$[6]^{2+}$

\begin{tabular}{|c|c|c|c|}
\hline Atom & $x$ & Y & Z \\
\hline $\mathrm{C}$ & -3.26844300 & 1. 09216900 & 2. 23163700 \\
\hline $\mathrm{C}$ & -3.23479700 & 3. 03327900 & 0.93341300 \\
\hline $\mathrm{C}$ & -4.18628800 & 3. 64732700 & 1. 74009100 \\
\hline $\mathrm{C}$ & -4.69596900 & 2. 94228300 & 2. 82884700 \\
\hline $\mathrm{C}$ & -4.23041400 & 1. 65426300 & 3. 07579100 \\
\hline $\mathrm{C}$ & -2.69359700 & -0.25304500 & 2. 42779600 \\
\hline $\mathrm{C}$ & -1.18953800 & -1.84528000 & 1. 62638200 \\
\hline $\mathrm{C}$ & -1.46049800 & -2.70636700 & 2. 68352500 \\
\hline $\mathrm{C}$ & -2.39503500 & -2.31644500 & 3.64113000 \\
\hline $\mathrm{C}$ & -3.01300200 & -1.07674100 & 3. 51179500 \\
\hline $\mathrm{H}$ & -2.81179900 & 3. 54315600 & 0.07719200 \\
\hline $\mathrm{H}$ & -4.51473700 & 4. 65412700 & 1. 51020700 \\
\hline $\mathrm{H}$ & -0.47489100 & -2.11393800 & 0.85830100 \\
\hline $\mathrm{H}$ & -0.94680500 & -3.65863600 & 2. 74428200 \\
\hline $\mathrm{N}$ & -1.79283800 & -0.65021900 & 1. 48749700 \\
\hline $\mathrm{N}$ & -2.78331400 & 1. 78644700 & 1. 16484500 \\
\hline $\mathrm{H}$ & -5.44282300 & 3. 38552800 & 3. 47833100 \\
\hline $\mathrm{H}$ & -2.63613900 & -2.96151100 & 4. 47892500 \\
\hline $\mathrm{N}$ & 0.33544400 & 1. 29083500 & 0.99765300 \\
\hline $\mathrm{C}$ & -0.10488800 & -1.16523600 & -2.14642600 \\
\hline $\mathrm{C}$ & 0.95761500 & -1.83335700 & -2.76227200 \\
\hline
\end{tabular}




\begin{tabular}{|c|c|c|c|}
\hline $\mathrm{C}$ & 2. 24289900 & -1.66927400 & -2.26943700 \\
\hline $\mathrm{C}$ & 2. 44838800 & -0.82868900 & -1.16386100 \\
\hline $\mathrm{C}$ & 1. 33060700 & -0.18916600 & -0.60135700 \\
\hline $\mathrm{C}$ & 1. 47342400 & 0.70156200 & 0.53591300 \\
\hline $\mathrm{C}$ & 2. 73200600 & 0.94187600 & 1. 11294400 \\
\hline $\mathrm{C}$ & 2. 80173000 & 1.81565000 & 2. 20952800 \\
\hline $\mathrm{C}$ & 1.63767300 & 2. 40591800 & 2. 67671900 \\
\hline $\mathrm{C}$ & 0.42277000 & 2. 12165900 & 2. 04638100 \\
\hline $\mathrm{H}$ & -1.12049300 & -1.27262000 & -2.50709300 \\
\hline $\mathrm{H}$ & 3. 09275500 & -2.17098100 & -2.71671300 \\
\hline $\mathrm{H}$ & 3. 76351500 & 2. 01222400 & 2. 66805400 \\
\hline $\mathrm{H}$ & 1. 65159500 & 3. 08554100 & 3. 52072600 \\
\hline $\mathrm{H}$ & -0.50274100 & 2.57183300 & 2. 38314500 \\
\hline $\mathrm{H}$ & 0.76023900 & -2.47105200 & -3.61598800 \\
\hline $\mathrm{H}$ & -4.61597100 & 1. 09405700 & 3. 91765000 \\
\hline $\mathrm{H}$ & -3.73150400 & -0.75302800 & 4. 25367600 \\
\hline $\mathrm{N}$ & 0.06935100 & -0.36458100 & -1.08479100 \\
\hline $\mathrm{C}$ & -0.28561200 & 3. 17320400 & -1.66458200 \\
\hline $\mathrm{C}$ & -0.25218100 & 4. 08469700 & -2.71870100 \\
\hline $\mathrm{C}$ & -1.23263500 & 4. 01630700 & -3.70892400 \\
\hline $\mathrm{C}$ & -2.21702300 & 3. 03710600 & -3.61042600 \\
\hline $\mathrm{C}$ & -2.19229500 & 2. 15363600 & -2.52681900 \\
\hline $\mathrm{C}$ & -3.17896600 & 1. 10998100 & -2.34621400 \\
\hline $\mathrm{C}$ & -4.11167600 & -0.64280300 & -1.10998800 \\
\hline
\end{tabular}




\begin{tabular}{|c|c|c|c|}
\hline $\mathrm{C}$ & -6.47265200 & -1.22833200 & -1.10005100 \\
\hline $\mathrm{C}$ & -6.17747500 & -2.56645200 & -0.72464900 \\
\hline $\mathrm{C}$ & -4.80894700 & -2.89747100 & -0.53245600 \\
\hline $\mathrm{N}$ & -1.23079200 & 2. 22410200 & -1.56077100 \\
\hline $\mathrm{N}$ & -3.07343800 & 0.29746300 & -1.33305600 \\
\hline $\mathrm{H}$ & -1.23070300 & 4. 71247900 & -4.54050000 \\
\hline $\mathrm{H}$ & -3.00005500 & 2. 94712600 & -4.35499700 \\
\hline $\mathrm{H}$ & -3.98707600 & 1. 01286100 & -3.06768200 \\
\hline $\mathrm{H}$ & -7.49917800 & -0.90897700 & -1.22569200 \\
\hline $\mathrm{H}$ & -4.52458600 & -3.90194000 & -0.24678800 \\
\hline $\mathrm{C}$ & -5.46353200 & -0.29940400 & -1.29574100 \\
\hline $\mathrm{H}$ & -5.73084600 & 0.72034500 & -1.55568800 \\
\hline $\mathrm{C}$ & -3.81033300 & -1.95350300 & -0.70780500 \\
\hline $\mathrm{H}$ & -2.77735700 & -2.24766500 & -0.57038900 \\
\hline $\mathrm{N}$ & -7.16988300 & -3.49436300 & -0.54525700 \\
\hline $\mathrm{C}$ & -6.83980900 & -4.85006400 & -0.12379900 \\
\hline $\mathrm{H}$ & -6.33364000 & -4.86128000 & 0.84984400 \\
\hline $\mathrm{H}$ & -7.75802800 & -5.42904800 & -0.03374400 \\
\hline $\mathrm{H}$ & -6.19157300 & -5.35392000 & -0.85172900 \\
\hline C & -8.56509400 & -3.12524700 & -0.74931200 \\
\hline $\mathrm{H}$ & -8.74190000 & -2.76650900 & -1.77070700 \\
\hline $\mathrm{H}$ & -9.19300600 & -4.00024500 & -0.58630200 \\
\hline $\mathrm{H}$ & -8.88623800 & -2.34135000 & -0.05120600 \\
\hline $\mathrm{Ru}$ & -1.41468800 & 0.74521700 & -0.05515200 \\
\hline
\end{tabular}




\begin{tabular}{|c|c|c|c|}
\hline $\mathrm{C}$ & 3. 91653200 & 0.28430500 & 0.55353100 \\
\hline $\mathrm{C}$ & 6. 17923700 & -0.09707400 & 0.56861500 \\
\hline $\mathrm{C}$ & 6. 03827900 & -0.97937200 & -0.56972100 \\
\hline $\mathrm{C}$ & 3. 77534600 & -0.59863000 & -0.58491500 \\
\hline $\mathrm{C}$ & 7. 44818700 & 0.12405400 & 1. 12087800 \\
\hline $\mathrm{C}$ & 7. 17254100 & -1.60282300 & -1.10731100 \\
\hline $\mathrm{C}$ & 8. 43959800 & -1.38221200 & -0.55757300 \\
\hline $\mathrm{C}$ & 8. 58090700 & -0.49686100 & 0.58469400 \\
\hline $\mathrm{C}$ & 9. 88724800 & -0.28490000 & 1. 13110500 \\
\hline $\mathrm{H}$ & 9. 99073000 & 0.37790700 & 1. 98526900 \\
\hline $\mathrm{C}$ & 10. 98160300 & -0.90370100 & 0.58854000 \\
\hline $\mathrm{C}$ & 10.84260200 & -1.77496100 & -0.53541000 \\
\hline $\mathrm{C}$ & 9. 61254100 & -2.00691500 & -1.09050100 \\
\hline $\mathrm{H}$ & 7. 53351700 & 0.78925200 & 1. 97460400 \\
\hline $\mathrm{H}$ & 7. 04684500 & -2.26125400 & -1.96129100 \\
\hline $\mathrm{H}$ & 11.96744900 & -0.73561500 & 1. 01100200 \\
\hline $\mathrm{H}$ & 11.72523300 & -2.25404600 & -0.94779400 \\
\hline $\mathrm{H}$ & 9. 50482300 & -2.66875900 & -1.94489000 \\
\hline $\mathrm{N}$ & 4. 81497300 & -1.20717600 & -1.12196100 \\
\hline $\mathrm{N}$ & 5. 09096900 & 0.51952000 & 1. 10569600 \\
\hline $\mathrm{H}$ & 0.53335800 & 4. 83064300 & -2.75199900 \\
\hline $\mathrm{H}$ & 0.45879400 & 3. 20186700 & -0.87836500 \\
\hline
\end{tabular}




\section{$[7]^{2+}$}

\begin{tabular}{|c|c|c|c|}
\hline Atom & $x$ & Y & Z \\
\hline $\mathrm{C}$ & -3.29719300 & 0.00555900 & 2. 44157100 \\
\hline $\mathrm{C}$ & -3.34113200 & 2. 27951100 & 1. 90852600 \\
\hline $\mathrm{C}$ & -4.29278000 & 2. 53860200 & 2. 88886800 \\
\hline $\mathrm{C}$ & -4.76003200 & 1. 47987900 & 3. 66558400 \\
\hline $\mathrm{C}$ & -4.25544000 & 0.20249100 & 3. 43959000 \\
\hline $\mathrm{C}$ & -2.67924300 & -1.30069200 & 2. 14266400 \\
\hline $\mathrm{C}$ & -1.13561100 & -2.44866400 & 0.82183500 \\
\hline $\mathrm{C}$ & -1.36501500 & -3.63933200 & 1. 50149300 \\
\hline $\mathrm{C}$ & -2.29953900 & -3.65034100 & 2. 53515500 \\
\hline $\mathrm{C}$ & -2.95938200 & -2.46872000 & 2. 85804600 \\
\hline $\mathrm{H}$ & -2.94943400 & 3. 06860100 & 1. 27950000 \\
\hline $\mathrm{H}$ & -4.65435500 & 3. 55028300 & 3. 03065700 \\
\hline $\mathrm{H}$ & -0.42552100 & -2.40082400 & 0.00581500 \\
\hline $\mathrm{H}$ & -0.82004500 & -4.53175200 & 1. 21705900 \\
\hline $\mathrm{N}$ & -1.77814800 & -1.30505400 & 1. 12148400 \\
\hline $\mathrm{N}$ & -2.85182000 & 1. 04602000 & 1. 68454600 \\
\hline $\mathrm{H}$ & -5.50471600 & 1. 64277600 & 4. 43696800 \\
\hline $\mathrm{H}$ & -2.50935800 & -4.56051700 & 3. 08620500 \\
\hline $\mathrm{N}$ & 0.27674500 & 0.59953500 & 1. 40512200 \\
\hline $\mathrm{C}$ & -0.10484500 & -0.32376500 & -2.48451200 \\
\hline $\mathrm{C}$ & 0.96874900 & -0.68723900 & -3.30262600 \\
\hline $\mathrm{C}$ & 2. 23951900 & -0.78019200 & -2.75692600 \\
\hline
\end{tabular}




\begin{tabular}{|c|c|c|c|}
\hline $\mathrm{C}$ & 2. 41959900 & -0.49535800 & -1.39412700 \\
\hline $\mathrm{C}$ & 1. 29365400 & -0.12187400 & -0.64024000 \\
\hline $\mathrm{C}$ & 1. 41300500 & 0.20003700 & 0.77004300 \\
\hline $\mathrm{C}$ & 2. 65041000 & 0.10601100 & 1. 43053800 \\
\hline $\mathrm{C}$ & 2. 69475700 & 0.40924900 & 2. 80029500 \\
\hline $\mathrm{C}$ & 1. 52752500 & 0.78806400 & 3. 44547800 \\
\hline $\mathrm{C}$ & 0.33828900 & 0.87506200 & 2. 71642200 \\
\hline $\mathrm{H}$ & -1.11082900 & -0.25250700 & -2.87920000 \\
\hline $\mathrm{H}$ & 3. 09650600 & -1.06751200 & -3.35437100 \\
\hline $\mathrm{H}$ & 3. 63960800 & 0.34122600 & 3. 32618000 \\
\hline $\mathrm{H}$ & 1. 52124600 & 1. 02599500 & 4. 50269900 \\
\hline $\mathrm{H}$ & -0.58518600 & 1. 18755000 & 3. 18806400 \\
\hline $\mathrm{H}$ & 0.79025400 & -0.89735000 & -4.35067300 \\
\hline $\mathrm{H}$ & -4.60681500 & -0.62991500 & 4. 03534500 \\
\hline $\mathrm{H}$ & -3.68027600 & -2.45661200 & 3. 66533500 \\
\hline $\mathrm{N}$ & 0.04512800 & -0.05129000 & -1.18020700 \\
\hline $\mathrm{C}$ & -0.63147700 & 3. 61380800 & -0.69676100 \\
\hline $\mathrm{C}$ & -0.76831800 & 4. 76651300 & -1.54657600 \\
\hline $\mathrm{C}$ & -1.80225200 & 4. 78227700 & -2.51214300 \\
\hline $\mathrm{C}$ & -2.64846000 & 3. 70850400 & -2.60322500 \\
\hline $\mathrm{C}$ & -2.45004800 & 2. 59757500 & -1.74895700 \\
\hline $\mathrm{C}$ & -3.33709600 & 1. 46031900 & -1.85482300 \\
\hline $\mathrm{C}$ & -4.07850300 & -0.64928700 & -1.19254000 \\
\hline $\mathrm{C}$ & -6.39511000 & -1.38781500 & -1.18776900 \\
\hline
\end{tabular}




\begin{tabular}{|c|c|c|c|}
\hline $\mathrm{C}$ & -6.00191300 & -2.74134700 & -1.36119500 \\
\hline $\mathrm{C}$ & -4.60787200 & -3.00510500 & -1.44403200 \\
\hline $\mathrm{N}$ & -1.46684600 & 2.52514500 & -0.82852500 \\
\hline $\mathrm{N}$ & -3.11970000 & 0.39942800 & -1.13620000 \\
\hline $\mathrm{H}$ & -1.91819700 & 5. 64507900 & -3.16052800 \\
\hline $\mathrm{H}$ & -3.46321100 & 3. 68412100 & -3.31768100 \\
\hline $\mathrm{H}$ & -4.16956500 & 1.50352100 & -2.55370800 \\
\hline $\mathrm{H}$ & -7.44196100 & -1.12890100 & -1.09503200 \\
\hline $\mathrm{H}$ & -4.25097500 & -4.01638300 & -1.59032100 \\
\hline $\mathrm{C}$ & -5.45450400 & -0.37178300 & -1.11775300 \\
\hline $\mathrm{H}$ & -5.78923400 & 0.64945300 & -0.96300200 \\
\hline $\mathrm{C}$ & -3.67599800 & -1.98430800 & -1.34837100 \\
\hline $\mathrm{H}$ & -2.62337600 & -2.22156900 & -1.44140900 \\
\hline $\mathrm{C}$ & 0.11913800 & 5.86227800 & -1.39150300 \\
\hline $\mathrm{C}$ & 1.09905000 & 5.84226000 & -0.42587000 \\
\hline $\mathrm{C}$ & 1.21846500 & 4. 72036800 & 0.42774800 \\
\hline $\mathrm{C}$ & 0.37847700 & 3. 63561100 & 0.29734500 \\
\hline $\mathrm{H}$ & 0.00103200 & 6.71869700 & -2.04839400 \\
\hline $\mathrm{H}$ & 1. 77358700 & 6.68427200 & -0.31038600 \\
\hline $\mathrm{H}$ & 1.98114300 & 4. 71332400 & 1. 20006900 \\
\hline $\mathrm{H}$ & 0.46909500 & 2. 79402800 & 0.96303300 \\
\hline $\mathrm{N}$ & -6.92599200 & -3.75111800 & -1.43902000 \\
\hline $\mathrm{C}$ & -6.49072000 & -5.13545300 & -1.57393800 \\
\hline $\mathrm{H}$ & -5.86115800 & -5.44705700 & -0.73083100 \\
\hline
\end{tabular}




\begin{tabular}{|c|c|c|c|}
\hline $\mathrm{H}$ & -7.36576800 & -5.78361300 & -1.59930100 \\
\hline $\mathrm{H}$ & -5.92428600 & -5.29480600 & -2.50018300 \\
\hline $\mathrm{C}$ & -8.34937900 & -3.45042600 & -1.35320400 \\
\hline $\mathrm{H}$ & -8.66605900 & -2.76622700 & -2.15000700 \\
\hline $\mathrm{H}$ & -8.91636300 & -4.37457600 & -1.45819100 \\
\hline $\mathrm{H}$ & -8.61336400 & -2.99701700 & -0.38888000 \\
\hline $\mathrm{Ru}$ & -1.47009100 & 0.54658300 & 0.17807900 \\
\hline C & 3. 84116400 & -0.29313400 & 0.67469000 \\
\hline $\mathrm{C}$ & 6. 09146500 & -0.73311100 & 0.58470600 \\
\hline $\mathrm{C}$ & 5. 97892500 & -1.01887800 & -0.82949000 \\
\hline $\mathrm{C}$ & 3. 72784900 & -0.58261500 & -0.73879900 \\
\hline C & 7. 34039500 & -0.82830800 & 1. 21349300 \\
\hline $\mathrm{C}$ & 7. 12036000 & -1.38686600 & -1.55466200 \\
\hline C & 8. 36743100 & -1.48118600 & -0.92847700 \\
\hline $\mathrm{C}$ & 8. 48021400 & -1.19503800 & 0.49065400 \\
\hline C & 9. 76650600 & -1.29755200 & 1. 11112300 \\
\hline $\mathrm{H}$ & 9. 84872200 & -1.08274100 & 2. 17258000 \\
\hline C & 10.86828300 & -1.65806100 & 0.38237500 \\
\hline C & 10. 75727000 & -1.93969500 & -1.01407000 \\
\hline $\mathrm{C}$ & 9. 54712000 & -1.85422600 & -1.64902900 \\
\hline $\mathrm{H}$ & 7. 40482200 & -0.61019200 & 2. 27506700 \\
\hline $\mathrm{H}$ & 7. 01620000 & -1.59737500 & -2.61457800 \\
\hline $\mathrm{H}$ & 11.83877000 & -1.73254800 & 0.86321600 \\
\hline $\mathrm{H}$ & 11. 64528000 & -2.22341200 & -1.57045300 \\
\hline
\end{tabular}




\begin{tabular}{llll}
\hline $\mathrm{H}$ & 9.46064800 & -2.06756200 & -2.71047900 \\
$\mathrm{~N}$ & 4.77510400 & -0.93408100 & -1.45941800 \\
$\mathrm{~N}$ & 4.99590500 & -0.37133200 & 1.30716700 \\
\hline
\end{tabular}

